\title{
CONTRA LA CORRIENTE: LA CRÍTICA CONSERVADORA -EN LO POLÍTICO Y ECONÓMICO- DURANTE LOS PRIMEROS AÑOS DEL Gobierno de CARlos IbáÑEZ del CAMPo (1927-1928)
}

[Against the Tide: the Conservative Criticism -Politically and EconomicallyDuring the First Years of Carlos Ibáñez del Campo's Government (1927-

1928)]

\author{
Enrique Brahm García* \\ Universidad de los Andes, Santiago, Chile
}

\begin{abstract}
RESUMEN
Con la llegada al poder de Carlos Ibáńez del Campo junto a su equipo de hombres nuevos en 1927 , se inició en Chile un acelerado proceso de reformas políticas y administrativas y también económicas. En lo político tendió a consolidarse un régimen presidencial autoritario. Por su parte el intervencionismo y el proteccionismo fueron los rasgos clave de la política económica. Dichas reformas marcarían la tendencia dominante para los decenios centrales de la historia del siglo XX en Chile. En ese contexto llama la atención el hecho de que la dirigencia del partido Conservador y su principal órgano de prensa, El Diario Ilustrado, hayan podido seguir defendiendo, contra la corriente $y$,
\end{abstract}

\begin{abstract}
With Carlos Ibáñez del Campo arrival to power with his team of $\mathrm{new}$ m e $\mathrm{n}$ on 1927, Chile began an accelerated process of political, administrative and also economics reforms. In the political aspect, it tended to consolidate an authoritarian presidential regime. For its part, the interventionism and protectionism were the key traits of the economic policy. Those reforms would mark the dominant trend for the central decades of the $20^{\text {th }}$ century history in Chile. In that context draws attention the fact that the conservative party leadership and its main press organ, the Diario Ilustrado, have been able to continue defending, against the tide and, as can be seen from the review of the press of the time, the liberal
\end{abstract}

RECIBIDO el 30 de noviembre de 2017 y ACEPTADO el 23 de mayo de 2018

* Doctor en Derecho por la Universidad de Frankfurt/M. Profesor de la Facultad de Derecho y del Instituto de Historia de la Universidad de los Andes (Santiago de Chile). Correo electrónico: ebrahm@uandes.cl. Dirección postal Universidad de los Andes, Facultad de Derecho, Av. Monseñor Álvaro del Portillo 12.455, Las Condes. Santiago. Este artículo se enmarca en el proyecto Fondecyt regular no 1151403. 
como se desprende de la revisión de la prensa de la época, el régimen liberal parlamentario y el liberalismo económico clásico.

Palabras clave

Partido Conservador Chileno - Carlos Ibáñez - intervencionismo y liberalismo económico - presidencialismo y parlamentarismo. parliamentary and the classical economics liberalism.

\section{KeYWORDS}

Chilean Conservative Party Carlos Ibáñez - interventionism and economic liberalism - presidentialism and parliamentarism.

\section{INTRODUCCIÓN}

Con la intervención militar de septiembre de 1924 llegó a su fin el Régimen Parlamentario y se inició una nueva época en la historia de Chile ${ }^{1}$. En lo político el cambio fundamental fue el establecimiento de un régimen presidencial en la Constitución Política de 1925, mientras que en lo económico se empezó a avanzar hacia un sistema intervencionista y proteccionista en el que el estado pasaría a desempeñar un rol protagónico en desmedro de los privados ${ }^{2}$. Ambas tendencias tomaron particular fuerza a partir de la llegada al poder de Carlos Ibáñez del Campo, quién se irguió como el caudillo del movimiento impulsado por la oficialidad joven del Ejército. Con su nombramiento como Ministro del Interior del gobierno de Emiliano Figueroa el 9 de febrero de 1927, cargo al que llegó acompañado de un e qu i p o ministerial integrado por los que el mismo llamaría h o m b r e s n u e v o s -Pablo Ramírez en el Ministerio de Hacienda y Conrado Ríos en el de Relaciones Exteriores, fueron los más representativos-, y luego en su calidad de vicepresidente (7 de abril de 1927) y, finalmente de presidente de la República (21 de julio de 1927), el autoritarismo político y el intervencionismo económico adquirirían particular fuerza ${ }^{3}$. Más todavía, a partir de ese momento se consolidaría

${ }^{1}$ La bibliografía al respecto es amplísima, pero pueden consultarse, Millar CARVACHO, René, Significado y antecedentes del movimiento militar de 1924 en Historia, 11 (Santiago, 1973), pp. 7-102; Nunn, Frederick, Chilean Politics, 1920-1931: the honorable Missions of the Armed Forces (Albuquerque, New Mexico, University of New Mexico Press, 1970); CorreA, Sofía y otros, Historia del siglo XX chileno (Santiago, Editorial Sudamericana, 2001), pp. 94 ss.; ColLier, Simon y SATER, William Historia de Chile 1808-1994 (España, Cambrigde University Press, 1998) pp. 189 ss.; SCOTT, Harry Pensando el Chile nuevo. Las ideas de la revolución de los tenientes y el primer gobierno de Ibáñez, 1924-1931 (Santiago, Centro de Estudios Bicentenario, 2009), pp. 51 ss.; Vial Correa, Gonzalo, Historia de Chile (1891-1973), Vol. III: Arturo Alessandri y los golpes militares (1920-1925) (Santiago, Santillana, 1986), pp. 366 ss.; Monreal, Enrique, Historia completa y documentada del período revolucionario 1924-1925 (Santiago, Imp. Nacional, 1929).

${ }^{2}$ Góngora, Mario, Ensayo histórico sobre la noción de Estado en Chile en los siglos XIX y XX (Santiago, Editorial La Ciudad, 1981), pp. 57ss.; Brahm García, Enrique; Bertelsen Repetto, Raúl; Amunátegui Echeverría, Andrés, Régimen de gobierno en Chile. ¿Presidencialismo o Parlamentarismo? 1925-1973 (Santiago, Editorial Jurídica de Chile, 2002); BraHm García, Enrique, Propiedad sin libertad: Chile 1925-1973. Aspectos relevantes en el avance de la legislación socializadora (Santiago, Ediciones de la Universidad de los Andes, 1999); Meller, Patricio, Un siglo de economía política chilena: (1890-1990) (Santiago, Editorial Andrés Bello, 1996).

${ }^{3}$ SCOTt, Harry, cit. (n.1) y Vial Correa, Gonzalo, Historia de Chile (1891-1973), Vol. IV: 
una tendencia que, más allá de fluctuaciones ocasionales, sería una constante en la historia nacional durante buena parte del siglo XX. En efecto, la defensa de las prerrogativas del presidente de la República frente a los otros poderes del estado y la presión socializadora que ejercería el gobierno irían in crescendo en las décadas siguientes, más allá de la persona o partidos que estuvieran en el poder ${ }^{4}$.

En ese sentido los dos primeros años del gobierno de Carlos Ibáñez fueron particularmente importantes. Después del débil mandato de Emiliano Figueroa, durante el cual parecían volver por sus fueros las prácticas parlamentarias y los partidos tradicionales ${ }^{5}$, Ibáñez llevaría al extremo el autoritarismo presidencial -de ahí que se haya calificado su gobierno como una d i c t a d u r a ${ }^{6}-$, y se llevaría adelante una profunda reforma en lo económico y administrativo -obra sobre todo de su Ministro Pablo Ramírez ${ }^{7}$ - que sentaría las bases del estado interventor en desmedro de los principios del liberalismo económico clásico ${ }^{8}$.

Llama la atención, en ese contexto, como todavía durante los años 1927 y 1928 sectores dirigentes del Partido Conservador que se expresaban, en lo fundamental, a través de El Diario Ilustrado ${ }^{9}$, siguieron defendiendo, contra la corriente y pese a la amenaza de censura y de deportación, el régimen parlamentario y las bondades del liberalismo económico. El contraste entre el discurso del gobierno de Ibáñez en lo político y económico y la posición contraria defendida por los conservadores, tal cual quedó expresada en la prensa de la época, es la cuestión que se estudia en el presente artículo.

La dictadura de Ibáñez (1925-1931) (Santiago, Editorial Fundación, 1996); VICUÑA, Carlos, La tirania en Chile (Santiago, Ediciones LOM, 2002).

${ }^{4}$ Brahm, Enrique; Bertelsen, Raúl; Amunátegui, Andrés, cit. (n. 2) y Brahm, Enrique, Propiedad sin libertad, cit. (n. 2).

${ }_{5}$ Donoso Letelier, Crescente, Notas sobre el origen, acatamiento y desgaste del régimen presidencial 1925-1973, en Historia, 13 (Santiago, 1976), pp. 271-352.

${ }^{6}$ Vicuña, Carlos, cit. (n. 3) y Vial, Gonzalo, Vol. IV, cit. (n. 3).

7 Esponda, Jaime, Pablo Ramírez. El chileno desconocido, (Santiago, RIL Editores, 2013); Silva, Patricio, En el nombre de la razón. Tecnócratas y politica en Chile (Santiago, Ediciones Universidad Diego Portales, 2010).

${ }^{8}$ Bernedo, Patricio, Prosperidad económica bajo Carlos Ibáñez del Campo, 1927-1929. La dimensión internacional de un programa económico de gobierno, en Historia, 24 (Santiago, 1989), pp. 5-105; Ibấnez Santa María, Adolfo, Los ingenieros, el Estado y la política en Chile. Del Ministerio de Fomento (1927) a la Corporación de Fomento de la Producción (1939), en Historia, 18 (Santiago, 1983), pp. 45-102; Cruz, Nicolás, El Gobierno de Ibáñez a través de la prensa (Santiago, Instituto Chileno de Estudios Humanísticos, 1980), inédito.

${ }^{9}$ Ello sin perjuicio de que dentro del Partido Conservador y en otros medios de prensa conservadores se defendieran también ideas muy distintas y hasta contrapuestas a las defendidas por la dirigencia santiaguina y El Diario Ilustrado. Cfr. BraHM GarCía, Enrique, La Unión y el Partido Conservador de Valparaíso: ¿una posición divergente en el conservantismo en medio de la crisis institucional de 1925?, en Revista de Estudios Histórico-Jurídicos, 38 (Valparaíso, 2016), pp. 395-419 y Brahm GarCía, Enrique, El Partido Conservador frente a la crisis constitucional de 1925, Revista Chilena de Derecho, 44/1 (Santiago, 2017), pp. 261-285. 


\section{IBÁÑEZ, LOS H O M B R E S N U E V O S Y SU PROGRAMA}

POLÍTICO

La llegada a la Presidencia de la República de Carlos Ibáñez del Campo en el mes de julio de 1927 fue recibida por importantes sectores de la población ${ }^{10}$ y de la opinión pública chilena con la esperanza de que se terminarían de concretar durante su mandato los grandes cambios que habían empezado a tomar forma a partir la intervención militar de 1924. La retórica dominante estaba llena de alusiones al cierre de una etapa de la historia de Chile y al comienzo de una nueva época radicalmente distinta que tendría en Ibáñez su adalid. Un editorial de $E l$ Mercurio, a propósito de su toma de posesión del cargo, señalaba que "la hora es solemne, porque el presidente Ibáñez recibe la investidura cuando estamos pasando por una profunda evolución política y social, llena de dificultades como todos los períodos de transformación de una nacionalidad, y el país entero fija sus miradas en el elegido, centro de las esperanzas y promesa de mejores días". "Sólo acertamos a darnos cuenta -agregaba más adelante- de que Chile se rehace: de que muchas instituciones, antes miradas como eternas, han sido derribadas; de que muchas costumbres que parecían tradiciones sagradas han cedido el paso a nuevos modos de obrar y de pensar; muchos aspectos de nuestra sociabilidad están siendo barridos por un viento que viene de las regiones aún misteriosas del futuro, que sería estéril esfuerzo el que se intentara con el fin de detener la evolución". Así podía concluir que "la fe nacional se concentra hoy en la persona del Presidente"; que él era "la esperanza cierta de que podemos llegar al término de la larga crisis política y social ${ }^{11}$.

Parecía concretarse aquello que ya se reclamaba en agosto de 1925 en el diario Acción, cuando se afirmaba en un artículo editorial que "después de toda revolución es necesario un gobierno fuerte de un dictador: Vicente Huidobro expresa que es más democrático un tirano que sepa hacer el bien a su Patria, aunque sea a la fuerza, que no una docena de políticos corrompidos se coman el pan del pueblo". Luego agregaba: "Hace ya tiempo que pedimos un Portales, un hombre de su talla que necesitamos para comenzar la regeneración de la Patria y para conseguir su objeto debe apoyarse en la juventud que es la única fuerza aún no corrompida por la politiquería"12.

La promesa estaba en el futuro, por lo que no se podía volver atrás. "La resurrección de los viejos sistemas -se señalaba en Sucesos, una revista cercana al gobierno- sería la destrucción de la gran obra de regeneración nacional" ${ }^{13}$. En palabras de Ismael Edwards Matte, ministro del Interior del gobierno de Ibáñez, "autoridad fuerte, inspirada en la justicia y en el apoyo a todos los que producen orientada hacia el porvenir y no anclada en los perjuicios de lo que ya pasó, preparadora de la armonía y no del odio, eso es y será nuestro Gobierno, eso

${ }^{10}$ Al haber obtenido más del $90 \%$ de los votos, Sucesos podía afirmar que Ibáñez tenía tras de sí "la unanimidad del país". Sucesos (26 mayo 1927), p. 20.

${ }_{11}$ El Mercurio (21 julio 1927), p. 3.

12 Acción (20 agosto 1925), p. 1.

13 Sucesos (12 julio 1928), p. 19. 
será el futuro de nuestro país. Dejen de esperar otra cosa los que creen posible la restauración de un régimen arcaico que produjo ya todos sus bienes y todos sus males: la historia no retrocede" 14 .

El elemento utópico y revolucionario latente se pondría de manifiesto también al anunciar Ibáñez la conformación del ministerio con el que en el mes de febrero de 1927 se pondría por primera vez a la cabeza del gobierno al asumir como ministro del Interior. En palabras muchas veces citadas afirmaría que "había que abandonar a los que se han quedado en los pliegues del pasado y dar paso a los hombres que tienen sus pupilas abiertas al amanecer" ${ }^{15}$. Ya no serían los antiguos políticos los que manejarían el país, sino los h o m b r e s n u e vos, "no gastados por la política ni endurecidos a nobles ambiciones por el interés de los negocios"16. Según se comentaba en Sucesos, "el país tiene puestas sus esperanzas en la obra depuradora de los hombres nuevos" ${ }^{17}$. Ellos debían ser más eficaces "que los hombres viejos, de alma ya gastada, de impulsos romos por la práctica y la experiencia. Los pueblos necesitan sacudirse de la modorra que provoca el exceso de experiencia, que es lo mismo que decir desconfianza" ${ }^{18}$.

A diferencia del régimen político pasado, del que se abominaba, se aspiraba ahora a la "reconstrucción de la autoridad"19, a satisfacer el "ansia nacional de autoridad" no concretada en los años que siguieron a la intervención militar de septiembre ${ }^{20}$. El mismo Ibáñez se había encargado de insistir en que en él se encarnaría el gobierno fuerte que el país necesitaba. Por ejemplo, en su conocido discurso ante las cámaras de octubre de 1926, donde afirmó: "Es necesario dejar establecido clara y francamente que el país clama por robustecer el principio de autoridad; que anhela acabar con la anarquía, enemiga de todo progreso" ${ }^{21}$. Mientras que en febrero del año siguiente afirmaba: "El país necesita el robustecimiento del Ejecutivo y un máximum del desarrollo del sentimiento nacionalista, que detesta la acción dilatoria y estéril de los partidos políticos y que desea un Gobierno fuerte, resuelto a afrontar sin vacilaciones y con prescindencia de los intereses partidistas los graves problemas nacionales" ${ }^{22}$. Como símbolo de la importancia que debía adquirir el presidente de la República, Ibáñez recibiría en una ceremonia solemne, celebrada en el Salón de Honor del palacio de La Moneda, la banda presidencial que había utilizado el expresidente Balmaceda ${ }^{23}$.

${ }^{14}$ La Nación (6 julio 1928), p. 1. "La resurrección de los viejos sistemas sería la destrucción de la gran obra de regeneración nacional”, se afirmaba en Sucesos. "El Gobierno [...] no se conformará con ser una etapa intermedia”. Sucesos (12 julio 1928), p. 19.

15 La Nación (9 febrero 1927), p. 11.

16 Sucesos (17 febrero 1927), p. 20.

17 Sucesos (28 abril 1927), p. 19.

18 Sucesos (17 febrero 1927), p. 20. “Se desea hacer política nueva con hombres nuevos", señalaba Jorge Schneider en La Nación (12 febrero 1927), p. 3.

19 Sucesos (14 abril 1927), p. 19.

${ }^{20}$ El Mercurio (16 abril 1927), p. 3. Se requería "un Gobierno fuerte que respete y haga respetar las leyes”, se señalaba en El Mercurio (5 mayo 1927), p. 3.

${ }^{21}$ La Nación (9 febrero 1927), p. 11.

${ }^{22}$ La Nación (9 febrero 1927), p. 11.

${ }^{23}$ El Diario Ilustrado (20 julio 1927), p. 6. 
En esa línea el discurso de Ibáñez y de quienes lo apoyaban apuntaba a que después del ensayo fallido de Emiliano Figueroa, debía hacerse plenamente efectivo el régimen presidencial consagrado en la Constitución de 1925, que se consideraba obra fundamental del movimiento militar ${ }^{24}$. Ello debía entenderse también en el sentido de que el gobierno de Ibáñez no se concebía a sí mismo como una dictadura militar ${ }^{25}$. Pero en pos del robustecimiento del principio de autoridad, se iba todavía un paso más allá, como se desprende claramente de las palabras pronunciadas por Ibáñez en su mensaje presidencial -todavía en calidad de vicepresidente de la República- de mayo de 1927. "Espero cooperación, diría dirigiéndose al Congreso, pero si por desgracia, me fuera negada; si intenciones aviesas pretendieran perturbar la obra honrada de un Gobierno cuya finalidad suprema y única es el bien de la Patria, no omitiré sacrificios propios ni ajenos, para guiar al país por la senda justa, para mantener el orden, aunque al término de mi período, en vez de poder declarar que me he ceñido estrictamente a las leyes, sólo pudiera afirmar, repitiendo la frase histórica: 'Juro que he salvado a la República'"26. Esto es, la Constitución no sería impedimento, por ejemplo, para detener y deportar -al margen de toda legalidad-a una gran cantidad de políticos y personalidades de distinto signo y características, cuyo común denominador sería el que no simpatizaban con el nuevo régimen ${ }^{27}$.

El fortalecimiento de la autoridad se estimaba clave para impulsar un proceso de "purificación nacional" 28 y de "regeneración nacional" 29 , porque, como señalaba en una circular el Ministro de Guerra Bartolomé Blanche, los últimos 37 años de la historia nacional habrían estado caracterizados por "un funesto desgobierno, fruto de la indolencia colectiva, de la inmoralidad y corrupción de una parte de los hombres dirigentes" 30 . Ibáñez, por su parte, declaraba a la prensa en marzo de 1927 que "para hacer imperar la moral continuaremos inflexiblemente nuestra tarea depuradora. Extirparemos los males y la podredumbre acumulados durante tantos años de desorden administrativo y de compadrazgos políticos" ${ }^{31}$. $\mathrm{O}$, expre-

${ }^{24}$ El 4 de mayo de 1927 (p. 3) se señalaba en un editorial de El Mercurio que "existía el deseo de que la Constitución de 1925 sea prácticamente aplicada y que se inicie en forma regular el nuevo sistema de Gobierno que ella implantó”.

25 En discurso pronunciado, todavía en su calidad de Vicepresidente de la República, a bordo del acorazado Latorre, señaló Ibáñez que él era "Presidente de todos los chilenos, y digo de todos los chilenos, porque no habría aceptado, en ningún caso, ser Presidente de bandos ni de partidos, ni tampoco ser impuesto por las fuerzas armadas a pesar de que son ellas las instituciones que más quiere el Jefe del Estado. Yo no habría aceptado en ninguna forma ser Presidente de la República llevado sólo por las fuerzas armadas porque no habría podido aceptar que se impusiera una semejante humillación a la democracia y al pueblo de mi país". La Nación (1 junio 1927), p. 11.

26 La Nación (22 mayo 1927), p. 19.

${ }^{27}$ Listas al respecto pueden verse en El Mercurio (26 febrero 1927), p. 8 y (27 febrero 1927), p. 22.

${ }_{28}$ Palabras del Ministro del Interior Enrique Balmaceda, citadas en El Mercurio (31 mayo de 1927), p. 13.

29 Sucesos (12 julio 1928), p. 19.

30 El Mercurio (7 julio 1927), p. 12.

31 La Nación (13 marzo 1927), p 17. 
sado con las palabras de la revista gobiernista Sucesos, "lo mismo que cuando se deshace una casa vieja, cada viga, cada ladrillo, cada piedra del cimiento aparecen huecos llenos de gusanos que están royendo la base, así al remecer cada organismo administrativo se ha comprobado la corrupción que había abajo" ${ }^{32}$. En el archivo personal de Carlos Ibánez se conserva una carta de 17 de febrero de 1927 en la que alguno de sus partidarios lo animaba a que "siga cortando la gangrena" y que siguiera "atacando el mal y la podredumbre donde quiera que se encuentre" 33 . Mientras que, en otra anterior, frente a uno de sus discursos pronunciados en la Cámara en su calidad de ministro de Defensa, se señalaba que merecía "el aplauso ferviente de los que anhelamos ver a nuestra patria libre de la podredumbre política y administrativa que la corroe" 34 .

La causa de la corrupción con la que quería terminar se encontraría en el régimen parlamentario que se había practicado en Chile -en realidad pseudo parlamentario, porque a él sólo se había llegado por la vía de dar una nueva interpretación a la Constitución de 1833- entre los años 1891 y $1924^{35}$. En carta a la "Sociedad de cortadores de carne", Ibáñez como ministro del Interior les agradecía "las felicitaciones que remitieron con motivo de las campañas recientemente emprendidas contra los elementos estériles o deshonestos y las prácticas ruinosas que habían germinado al amparo de un régimen de desenfrenado parlamentarismo" 36 . Mientras que, en un artículo editorial de ElMercurio, ya en enero de 1926, después de referirse a los “excesos del parlamentarismo en los países latinos”, señalaba que lo mismo habría ocurrido en Chile durante más de treinta años, lo que resultaba particularmente peligroso. "Desacreditado por su esterilidad y su influencia corruptora el sistema parlamentario, los pueblos se acogen por desesperación a lo que llaman los Gobiernos fuertes. Y estos Gobiernos fuertes, cuando no están encuadrados en un régimen nacional de equilibrio de los poderes, como el establecido en nuestra Constitución, degeneran rápidamente en dictaduras militares o civiles con apoyo militar" ${ }^{37}$. No se podía volver al parlamentarismo, sino que había que hacer realidad el régimen presidencial ${ }^{38}$.

Pero, detrás del régimen parlamentario -sostenían los partidarios del nuevo gobierno- se encontraban los partidos políticos históricos del Chile del siglo XIX y los tradicionales sectores dirigentes de la sociedad chilena, los cuales fueron también objeto de durísimas críticas. Según señalaba con particular dureza Conrado Ríos Gallardo, poco antes de asumir como Ministro de Relaciones Exteriores del gabinete de los h o m b r es n u e vos, "antes de la legislación revolucionaria el país vivía bajo la dictadura irresponsable de unos cuantos fumadores de habanos

32 Sucesos (17 mayo 1927), p. 19. La intervención militar habría apuntado a "detener la ola de corrupción política y administrativa que invadía el país”. Sucesos (21 julio 1927), p. 19.

33 Archivo Donoso Ibáñez (ADI) (privado) carta de 17 de febrero de 1927.

${ }^{34}$ ADI, carta de 20 de octubre de 1926.

35 Además de la literatura ya citada, puede consultarse Heise, Julio, Historia de Chile. El régimen parlamentario 1861-1925 (Santiago, Editorial Andrés Bello, 1974).

36 El Mercurio (26 marzo 1927), p. 21.

37 El Mercurio (19 enero 1926), p. 3.

38 Sucesos (12 julio 1929), p. 19. 
que usufructuaban las influencias parlamentarias. Bajo la tiranía de los partidos políticos que hacían escarnio de la ley electoral y bajo el látigo de numerosos especuladores de alto bordo que bajaban y sumían el cambio a su voluntad, sobre las espaldas de un pueblo oprimido y miserable, el país iba al desastre y a la vergüenza" ${ }^{39}$. Buena parte de los problemas que arrastraba Chile se atribuían a la politique ría ${ }^{40}$ y llegaba a anunciarse hasta el fin de los partidos ${ }^{41}$. El mismo Ibáñez, ya como presidente de la República, señalaba que "las luchas partidistas me parecen anacrónicas. No es hora de discutir, sino de obrar” ${ }^{2}$. Se daba ya por muertos a los viejos partidos, y se equivocaban -sostenía el ministro del Interior, Ismael Edwards Matte- los que soñaban con su resurrección, porque su "predominio significaría que colectividades nacidas para luchar en los problemas religiosos y políticos del siglo XIX, vendrían sin ninguna competencia a solucionar la cuestión económico-social que es el eje de la vida colectiva en el siglo XX"43.

Era evidente el tono anti oligárquico que dominaba el discurso entre los principales exponentes del nuevo régimen y que este, en la senda de la Revolución del 5 de septiembre, se proponía servir a los sectores más desposeídos de la sociedad. "Velaré por el estricto cumplimiento de las leyes sociales, expresaba Ibáñez en su Manifiesto al país de mayo de 1927, que a mi juicio son el fundamento de la paz social" 44 . Por su parte, su ministro del Interior Enrique Balmaceda, hablaba de la necesidad de volver a levantar "un gran ideal de justicia democrática y de igualdad social” 45 . Pero el bienestar social de los sectores populares debía alcanzarse sin recurrir a la violencia, sino por la vía de la cooperación entre trabajadores y empresarios. Si en este contexto se recuerda la crítica antes señalada al sistema de partidos y la necesidad que habría de centrar la política en las cuestiones económicas y materiales, resulta fácil entender que se haya insinuado la posibilidad de recurrir a fórmulas corporativas, las que estaban tan de moda en esos años ${ }^{46}$. En el Manifiesto antes citado, Ibáñez señalaba "que durante mi administración se ha de llegar a la preparación necesaria para entrar a la organización corporativa de las fuerzas productoras de la nación. La realización de este ideal traerá consigo el establecimiento de una sólida y fecunda armonía entre los diversos componentes

39 La Nación (3 febrero 1927), p. 3.

40 Sucesos (25 noviembre 1926), p. 33.

41 Sucesos (26 julio 1928), p. 8. "Los partidos, aunque aparenten vivir y hagan de vez en cuando ostentación de sus viejas ideas, están realmente muertos, y deben resucitar transformados conforme a las nuevas ideologías o acabarse".

42 La Nación (4 junio 1927), p. 3.

43 La Nación (6 de julio de 1928), p. 3. En un editorial del mismo diario de 11 de febrero de 1927, p. 3, se señalaba, en la misma línea, que los problemas del momento, en "forma casi exclusiva son de carácter económico y eminentemente práctico". Mientras que, en El Mercurio (3 mayo 1928), p. 3, se señalaba que "el problema palpitante de la vida nacional es un problema económico, de producción de riqueza, de trabajo”.

44 El Diario Ilustrado (9 mayo 1927), p. 9.

45 El Mercurio (25 mayo 1927), p. 7.

46 BaRTH, Boris, Europa nach dem grossen Krieg. Die Krise der Demokratie in der Zwischenkriegszeit 1918-1938, (Frankfurt/M., Campus Verlag, 2016); AldCrofT, Derek y otros, Europa en crisis, 1919-1939, (Madrid, Editorial Pablo Iglesias, 1991). 
de la sociedad, el desarrollo máximo de nuestras posibilidades económicas y una constante y disciplinada actividad productiva" ${ }^{47}$. La solución corporativista la defendería con particular fuerza Guillermo Edwards Matte, quién fuera ministro del Interior del gobierno de Carlos Ibáñez, citando a León Duguit ${ }^{48}$. En la misma línea se movía la UsRach (Unión Social Republicana de Asalariados de Chile), que se había constituido como partido para apoyar en 1925 la candidatura presidencial de José Santos Salas. En una exposición pública manifestaban su repudio a las cámaras políticas, "por ser organismos ineficaces, retardatarios y artificiales", y postulaban la necesidad de avanzar "hacia la organización corporativa del Estado", "levantando la función y el sindicato como fundamentos del orden nuevo" ${ }^{\prime 2}$. Parecía ser esta la tendencia de la época, según se observaba en algunos países europeos ${ }^{50}$.

Las soluciones corporativas debían posibilitar el que se superara la división de la sociedad en clases sociales antagónicas; debían hacerse imposibles tanto la lucha de clases preconizada por el marxismo, como el liberalismo individualista que tendía a atomizar a la sociedad. "El Gobierno combate con todas sus armas la desquiciadora utopía comunista, pero es también un obstáculo insalvable para el desarrollo de una reacción hacia los sistemas ultra-liberales del siglo pasado que significaban el triunfo de todos los egoísmos" ${ }^{51}$. El gobierno de Ibáñez, que se presentaba como una tercera vía entre el liberalismo y el socialismo, atacaría con particular fuerza al comunismo. "Yo no lo acepto en mi patria, diría el presidente de la República, ni como fuerza política ni como idealidad social" ${ }^{2}$, de ahí que sus dirigentes fueran perseguidos por el gobierno y muchos de ellos deportados, junto con los representantes de la o li ga rquía ${ }^{53}$.

Por último, debe señalarse también, que el nuevo régimen se concebía a sí mismo como caracterizado "por el más absoluto y acendrado nacionalismo". Según señalaba Carlos Ibáñez, "sólo una obra nacionalista [...] cuya norma sea el axioma patriótico de "Chile para los buenos chilenos" podrá ser útil y duradera" 54 .

47 El Diario Ilustrado (9 mayo 1927), p. 9.

${ }^{4}$ El Mercurio (11 septiembre 1928), pp. 1ss. y La Nación del mismo día, p. 13.

49 El Mercurio (5 de marzo de 1927), p. 11.

50 El mismo Juan Gómez Millas, en ese momento director del Instituto de Historia y Geografía y profesor de la Escuela Militar, en entrevista dada a El Mercurio (31 octubre 1928), p. 11, reconocía que "una de las modalidades del Estado moderno [...] es el aprovechamiento de las fuerzas de la colectividad, coordinadas para que surja una resultante con menos trabajo y con mayor provecho para todos. Es lo que yo llamo la voluntad de organización que proviene de la necesidad imperiosa de ordenar los factores sociales y establecer entre ellos las relaciones que, por ser parte de un mismo fenómeno, les corresponde mantener, para que surja entonces una unidad estatal que investigue y trabaje en beneficio de todos. Es lo que se ha llamado funcionalismo, que en el fondo no es más que la organización de las fuerzas productoras de la nación, sistematizadas por el Estado".

${ }^{51}$ La Nación (6 julio 1928), p 1. Cfr. Sucesos (12 julio 1928), p. 19.

52 El Mercurio (13 febrero 1927), p. 21. En Sucesos (8 septiembre 1927), p. 20, se señalaba que "el comunismo es un tumor social que es preciso extirpar con el hierro candente".

${ }^{53}$ Cfr., por ejemplo, La Nación (16 marzo 1928), p. 1; La Nación (17 marzo 1928), p. 15 y El Mercurio de los mismos días.

${ }^{54}$ La Nación (11 febrero 1927), p. 5. 


\section{A FAVOR DEL INTERVENCIONISMO ECONÓMICO DEL ESTADO}

El nacionalismo también sería determinante para dar forma a las políticas económicas impulsadas por el gobierno de Carlos Ibáñez. Como este señalaba en carta dirigida a Guillermo Edwards, su objetivo era "infiltrar en nuestro país, por todos los medios a nuestro alcance, el sentimiento nacionalista, aun cuando en este esfuerzo nos volvamos chauvinistas. ¡No importa! ¡ Vivir con lo nuestro, usar las cosas chilenas, nacionalizarnos hasta el máximum! Después de tantos años de adormecimiento colectivo necesitamos reaccionar con violencia" ${ }^{55}$. Nacionalismo económico que no era una completa novedad en $\mathrm{Chile}^{56}$, pero que a partir de ahora tomaría particular fuerza. "El concepto que preside nítidamente la orientación actual, se afirmaba en La Nación, es el de robustecer la idea de nacionalización" ${ }^{57}$. Pocos días antes el diario de gobierno había titulado: "La labor nacionalista del Gobierno sigue siendo aplaudida en el Congreso" 58 . Por lo demás, también desde fuera de los sectores de gobierno se constataba que era esa la línea dominante. Por ejemplo, el cónsul de Alemania en Valparaíso informaba a su gobierno con cierta preocupación que "no se puede negar que en el último tiempo en Chile la tendencia nacionalista es cada vez más fuerte y pronunciada" 59 , y que dominaba un "nacionalismo exacerbado" 00 en materias económicas.

De forma explícita se manifestaba Ibáñez crítico del sistema liberal dominante en entrevista que concedía a La Nación el 18 de marzo de 1927, donde constataba que "la inestabilidad y el desorden reinaban en la vida económica y social de Chile. Si estas fueran siempre las características de las sociedades viejas habría que reconocer que la libre competencia industrial bajo el régimen de propiedad privada habría hecho envejecer muy pronto a la sociedad chilena. Se habían formado clases con intereses diametralmente opuestos y, lo que es una aberración, creciendo enormemente la capacidad productiva del país, los consumos del pueblo acusaban apenas un sensible aumento" ${ }^{11}$.

Ello se traduciría en la adopción por parte del gobierno de una política económica anti liberal, caracterizada -como se tendrá oportunidad de ver-por un creciente intervencionismo económico del Estado y por la introducción de mecanismos proteccionistas. A nivel mundial esto no era una novedad, pues políticas de esas características habían empezado ya a tomar fuerza a partir de la crisis económica de 1873-1874 y, particularmente, con la Primera Guerra Mundial y sus secuelas y terminarían por ser popularizadas por los movimientos

55 La Nación (29 marzo 1927), p. 3.

56 Cfr. Bernedo, Patricio, cit., (n. 8) pp. 60 ss. Góngora, Mario, cit., (n. 2) pp. 34 ss.; Villalobos, Sergio y Sagredo, Rafael, El proteccionismo económico en Chile, siglo XIX (Santiago, Instituto de Estudios Superiores Blas Cañas, 1987).

57 La Nación (5 agosto 1927), p. 3 (art. de Sady Concha S.).

58 La Nación (1 agosto 1927), p. 7.

59 Archivo del Ministerio de Relaciones Exteriores de Alemania (PAAA) R79091. Carta de 10 de marzo de 1927.

60 PAAA R79091. Carta de 14 de junio de 1927.

${ }^{61}$ La Nación (18 marzo 1927), p. 3. 
de estilo fascista ${ }^{62}$. No es casualidad que Mussolini figurara con regularidad en

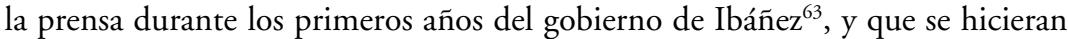
asociaciones entre las figuras fuertes de los gobiernos de Italia y de Chile ${ }^{64}$. En otro lugar ${ }^{65}$ habíamos insistido sobre todo en la influencia que habría tenido en Chile el modelo alemán -el socialis mo de estado, primero y luego el socialis mo de guerra, conocido y experimentado por los militares chilenos que tuvieron al ejército alemán como modelo-. En cambio, ahora nos parece que, por lo menos en materias económicas, el gobierno de Ibáñez estuvo mucho más cerca del modelo español del general Miguel Primo de Rivera, quien gobernó España entre 1923 y 1930. La descripción que de la política económica del dictador español hace su principal biógrafo, calzan casi a la perfección con las desarrolladas por Ibáñez y su ministro Pablo Ramírez. Shlomo Ben-Ami afirma que Primo de Rivera era "un intervencionista fanático", dispuesto a someter a la economía española "a un alto grado de dirigismo y tutela”; se debía fomentar la industria a través de una "supervisión estricta" y estaba dispuesto hasta llegar a nacionalizar ciertos rubros de la producción. Agregaba que "constituía un rasgo de muchos de los organismos intervencionistas de Primo de Rivera que se compusieran de representantes de los sectores económicos directamente relacionados con la esfera de actividad de la que se ocupaban los organismos respectivos". Sería su ideal el que España "pudiera satisfacer con sus propios productos sus necesidades vitales", para lo cual establecería altos aranceles para las importaciones -proteccion is mo defensivo-y promovería la creación de sistemas crediticios y otros medios para fomentar el comercio exterior - p r o t e c c i o $n$ is m o a c t iv o-. Impulsaría también un gigantesco plan de obras públicas, que incluía la construcción de edificios públicos, carreteras, de puertos y aeropuertos y hasta -al igual que Ibáñez con los inicios de Lan- pondría los fundamentos de la aviación comercial española. Para financiarlo, el gobierno español establecería un "presupuesto extraordinario" el que se financiaría "con el superávit del ordinario y los empréstitos públicos”, tal como haría Pablo Ramírez en Chile ${ }^{66}$.

62 Gall, Lothar, Zum Ausbildung und Charakter des Interventionsstaates, en Historische Zeitschrift, 227 (Oldenbourg, 1978), pp. 552-570; Nipperdey, Thomas, Deutsche Geschichte 1866-1918, Bd. II, Machtstaat vor der Demokratie (München, C.H. Beck, 1993); STOLLEIS, Michael, Geschichte des öffentlichen Rechts in Deutschland, Bd. III (München, C.H. Beck Verlag, 1999); Payne, Stanley Historia del Fascismo (Barcelona, Planeta, 1995).

${ }^{6}$ Cfr. por ejemplo, La Nación (6 diciembre 1927), p. 14; El Mercurio (29 julio 1928), p. 3 y (20 junio 1928), p. 3.

${ }^{64}$ Según se señalaba en El Mercurio (19 junio 1927), p. 23, en una película con noticias de la semana proyectada en los cines de Filadelfia en los Estados Unidos, aparecía el Vicepresidente de la República Carlos Ibáñes con el siguiente título: "El Mussolini de Chile, salvador del país en los momentos actuales". Para las relaciones entre Chile e Italia en el período puede consultarse Nocera, Raffaele, Duhart, Carmen Gloria, Alarcón, Camilo, Italia a través de los informes diplomáticos chilenos, 1924-1940 (Santiago, Colección de Informes Diplomáticos. Ministerio de Relaciones Exteriores de Chile, 2017).

${ }^{65}$ Brahm García, Enrique, Algunos aspectos del proceso de socialización del derecho de propiedad en Chile durante el gobierno del general Carlos Ibáñez del campo (1927-1931), en Rechtsgeschichte, 20 (Frankfurt/M., 2012), pp. 235 ss.

${ }^{66}$ Ben Ami, Shlomo, El cirujano de hierro. La dictadura de Primo de Rivera (1923-1930) (Barcelona, RBA Libros, 2012), pp. 222 ss. 
En el caso chileno, el paulatino alejamiento del modelo liberal hasta entonces dominante, había empezado ya a manifestarse con fuerza a partir de la intervención militar de 1924, y se concretaría de inmediato -por ejemplo-con la aprobación de un paquete de leyes s o cial es y la introducción de la p rog resivida de los impuestos ${ }^{67}$. Sobre esa base Ibáñez, que se consideraría a sí mismo siempre como el gran defensor de los principios que habían motivado la intervención militar ${ }^{68}$, impulsaría desde su gobierno la aprobación de una legislación socializadora, que apuntaba a restringir los derechos de libre disposición de los propietarios, y que llegaría hasta el extremo de limitar los montos de la indemnización en el caso de una serie de leyes que autorizaban la expropiación de inmuebles ${ }^{69}$.

Con una clara inspiración Keynesiana, y al igual de lo que estaba haciendo Primo de Rivera en España, como una forma de impulsar a Chile a la modernidad, reactivar la economía y hacerla crecer proveyéndola de medios adecuados, el gobierno de Ibáñez pondría en ejecución un ambicioso plan de obras públicas que incluía la construcción de carreteras, puertos y aeropuertos, entre otros ${ }^{70}$. "Los millones que el Gobierno invertirá en obras públicas, titulaba La Nación, van a beneficiar directamente a las clases populares. El trabajo que proporcionarán, facilitará la vida y distribuirá el circulante de uno a otro extremo del país, entonando las industrias y el comercio"71. El financiamiento de estas obras se haría a través del endeudamiento del estado el que para estos efectos contrataría empréstitos tanto internos como externos ${ }^{72}$. Desde el punto de vista presupuestario y para mantener los equilibrios exigidos en ese plano, al igual de lo que se estaba haciendo en España, se consultaría la existencia de dos presupuestos: junto al Ordinario tradicional se creó uno Extraordinario. Según se señalaba en oficio del Ministerio de Hacienda a la Cámara de Diputados, las entradas del Presupuesto Ordinario estarían constituidas "por el producto de los impuestos, derechos aduaneros, tarifas de servicios públicos, intereses de inversiones, rentas de arrendamiento de

${ }^{67}$ Cfr. Vial, Gonzalo, Historia de Chile, Vol. III, cit. (n. 1), pp. 393 ss., Brahm García, Enrique, La elección presidencial de 1925. El candidato equivocado, en SAN FranCISCO, Alejandro y Soto, Angel (eds.), Camino a La Moneda. Las elecciones presidenciales en la Historia de Chile 1920-2000 (Santiago, Centro de Estudios Bicentenario, 2005), pp. 39 ss. y BraHm García, Enrique, Propiedad sin libertad, cit. (n.2), pp. 67 ss.

68 "Mi presencia actual en el Ministerio del Interior -afirmaría Ibáñez- no tiene otra significación que el cumplimiento de los ideales revolucionarios tantas veces malogrados". La Nación (7 marzo 1927), p. 11.

69 El tema es estudiado en BraHm García, Enrique, Algunos aspectos, cit. (n. 65).

70 "El Senado despachó ayer totalmente el proyecto sobre un vasto plan de Obras Públicas", titulaba, por ejemplo, La Nación (2 febrero 1928), p. 5. "Caminos, ferrocarriles y obras de regadío que se construirán en el presente año", La Nación (10 febrero 1928), p. 13. "Que se construyan aeródromos en todas las ciudades de la República, es la idea que propicia el Gobierno”, La Nación (23 octubre 1927), p. 3.

${ }^{71}$ La Nación de 14 de enero de 1928, p. 14.

72 "El más grande empréstito interno que se haya lanzado", titulaba El Diario Ilustrado (12 julio1928), p. 1. Y en otro titular del mismo diario (12 febrero 1929), p. 5, se señalaba: "1.575 millones de pesos en obras y adquisiciones fiscales. Ayer fue promulgada la ley que autoriza la inversión de esta suma, que se obtendrá de empréstitos escalonados en seis años”. Cfr. BERNEDO, Patricio, cit., (n. 8) pp. 28 ss. y 53 ss. 
bienes fiscales y otros ingresos de orden 'normal y permanente". Mientras que los gastos serían "igualmente los de orden 'normal y permanente', es decir, aquellos incorporados al régimen ordinario de la administración y que se repiten en años sucesivos". En cambio, en el Presupuesto Extraordinario correspondería incluir "sólo las entradas ocasionales como, por ejemplo, los empréstitos, la venta de bienes fiscales, las conversiones de la deuda pública, los superávits no comprometidos del Presupuesto Ordinario y otras entradas de igual naturaleza”. Mientras que los gastos serían "por definición, aquellos que justificadamente puedan efectuarse con cargo a empréstitos y a otras entradas ocasionales", como, por ejemplo, "las nuevas obras públicas; las reparaciones acumuladas de años anteriores en las mismas obras públicas", etc. ${ }^{73}$.

En una entrevista a la escritora argentina Julia García, Ibáñez habría señalado que "el Estado tiene, pues, una gran misión que llenar para restablecer el equilibrio social", esto a propósito de que poco antes se había señalado que "hacer de la sociedad una representación disgregada, anárquica, en la que cada individuo es una unidad autónoma, ante la cual el Estado no intervendrá sino por el delito, por la falta o por los conflictos que se derivan del cumplimiento de los contratos es retrotraer el concepto a la prehistoria, volver a un mundo atomista y a una libertad que lleva al triunfo de los fuertes económicamente y a la esclavitud positiva de los débiles" ${ }^{\text {. }}$. Esto se concretaría en el hecho de que durante el gobierno de Carlos Ibáñez se tendería a forjar alianzas entre el estado y los gremios organizados para dirigir la economía. Por ejemplo, El Mercurio señalaba que el Ministro de Hacienda Pablo Ramírez habría señalado que su política respecto a la explotación del yodo, consistía "en darle al Gobierno una mayor intervención en la industria, a cuyo efecto había solicitado a la combinación que se otorgaran al Gobierno tres delegados con derecho a voto y veto en las resoluciones; asimismo había pedido a la combinación que aceptaran desde luego que el Gobierno pudiera en cualquier momento tomar el control del yodo; y que estas dos ideas del Ministerio habían sido aceptadas por el directorio" 75 . Y algo similar ocurriría con el salitre ${ }^{76}$. Así se impulsaría desde el Gobierno el asociacionismo empresarial, para facilitar la conducción de la economía por parte del gobierno ${ }^{77}$.

${ }^{73}$ El Diario Ilustrado (4 febrero 1929), p. 5. Cfr. El Diario Ilustrado (27 mayo 1928), p. 25 y (9 junio 1928), p. 5.

${ }^{74}$ La Nación (18 marzo 1927), p. 3.

${ }^{75}$ El Diario Ilustrado (15 abril 1927), p. 3.

${ }^{76}$ La Nación (25 agosto 1927), p. 3. Por lo demás, el impulso venía también de los privados. En banquete ofrecido al Ministro de Fomento Adolfo Ibáñez, un representante de los empresarios -Camilo Carrasco Bascuñán- señalaba: "Todo en nuestro país necesita coordinación para que lleguemos al éxito y para que no se malogren nuestros esfuerzos y sacrificios”. El Diario Ilustrado (13 octubre 1927), p. 10.

77 Como se señalaba en El Mercurio (11 diciembre 1927), p. 37, el ministro de Fomento, en reunión con agricultores y comerciantes de Temuco, se habría referido a la "necesidad de que los productores de esta región constituyan asociaciones que los representen, pues desde que se creó el Ministerio se estableció como norma que el Gobierno se entendiera con los productores únicamente por intermedio de sus respectivas asociaciones”. Poco antes había dirigido una circular a las diversas asociaciones del país en la que señalaba que no existía ningún otro medio 
Al contrario, se miraban con sospecha los emprendimientos individuales, sobre todo aquellos que no tenían relación directa con la producción. Así es como el gobierno estimaba por una parte que "el progreso económico del país está íntimamente ligado al abandono de la afición excesiva por las profesiones liberales, para dar preferencia a los estudios industriales en que se forman elementos de producción efectiva", como también criticaba la actividad comercial, tanto mayorista como minorista, porque "la especulación y el sistema de ventas con numerosos intermediarios", sólo contribuiría a provocar un alza en el coste de la vida ${ }^{78}$. En esa línea, y considerando que "el alza artificial de los artículos de consumo, y su adulteración, han llegado a extremos", es que se anunciaba la creación de la "Dirección General de Subsistencias, destinada a controlar las ventas y consumos de los artículos alimenticios de primera necesidad; a impedir la especulación con ellos y a reglamentar las exportaciones y las importaciones en forma que permita eliminar para siempre la posibilidad de que el pueblo carezca de alimentos sanos, abundantes y a precios módicos"79. Se preanunciaba lo que terminaría siendo el Comisariato General de Subsistencias de Precios, con sus radicales atribuciones de intervencionismo económica, obra del gobierno de Carlos Dávila, bajo la República Socialista de $1932^{80}$. Además, también en estas materias, el gobierno solicitaba la cooperación de los particulares, a los que llamaba a organizarse en “cooperativas agrícolas de consumos, de edificación, de producción y de crédito, y en sindicatos profesionales" 81 .

Elemento central de la política económica del gobierno ibañista sería el proteccionismo. Ya en febrero de 1927 Pablo Ramírez señalaba que el gobierno realizaría "rápidamente un programa vigoroso de protección activa de todas las industrias nacionales" ${ }^{82}$, lo que se concretaba un año después con la promulgación de un nuevo arancel aduanero el 22 de febrero de $1928^{83}$. Este texto marcaba una inflexión en la línea de proteger la industria nacional, aunque el proteccionismo no era una originalidad en Chile ${ }^{84}$, y también estaba a tono con lo que era una tendencia general de la época en buena parte del mundo ${ }^{85}$. Para El Mercurio, el nuevo Arancel introduciría "un proteccionismo industrial bien entendido, que será fecundo en buenos resultados tanto para los empresarios y capitalistas, como para los obreros", porque su aplicación redundaría en el "resurgimiento de las actividades fabriles, la absorción de los brazos desocupados, la atracción de nuevos capitales, el aumento de la producción y demás bienes que nacen de la actividad

más propicio "para obtener la cooperación de las fuerzas productoras del país que incitarlos a vigorizar el espíritu de asociación, a crear en todas las regiones del país intereses y aspiraciones colectivas". El Diario Ilustrado (23 octubre 1927), p. 25.

${ }^{78}$ Mensaje leido por S.E. el Vicepresidente de la República en la apertura del Congreso Nacional el 21 de mayo de 1927 (Santiago, Imprenta Nacional, 1927), pp. 37 y 43.

79 Mensaje, (n. 78), p. 44.

${ }^{80}$ Cfr. Brahm, Enrique, Propiedad sin libertad, cit. (n. 2), pp. 95 ss.

81 Brahm, Enrique, Propiedad sin libertad, cit. (n. 2), pp. 95 ss.

82 La Nación (23 febrero 1927), p. 6.

${ }^{83}$ Cfr. Bernedo, Patricio, cit. (n. 8) pp. 76 ss.

${ }^{84}$ Cfr. Villalobos, Sergio y Sagredo, Rafael, cit. (n. 56).

85 Bernedo, Patricio, cit. (n. 8), pp. 80 ss. 
general de los negocios" ${ }^{\text {. }}$. En todo caso, desde mucho antes venían dictándose normas que apuntaban a proteger a la industria nacional, como lo demuestra una visión panorámica de algunos titulares de la prensa. "El Ministerio de Hacienda dicta un importante decreto de protección a la industria del carbón. Se eximirá de los derechos de hospital, faros y balizas a los vapores que recalen en algún puerto chileno con el exclusivo objeto de proveerse de carbón nacional" "37; "Se protegerá la industria nacional del carbón. La Comisión Mixta de Arancel acuerda aumentar los derechos de importación del carbón extranjero" "88; "El salitre sintético no podrá entrar al país libre de derechos" ${ }^{89}$. Se promulgaría también una ley de protección de la marina mercante nacional ${ }^{90}$. Fuera de los aranceles, otra forma de proteger la industria nacional, era la invitación/exigencia que hacía el gobierno para que se consumieran productos nacionales con preferencia a los importados. Esa, por ejemplo, era la solicitud que hacía el ministro de Hacienda a las compañías extranjeras en julio de $1927^{91}$ y lo que planteaba el mismo Ibáñez en su Mensaje de 1927 al señalar que "como medio de proteger la industria nacional, se procura adquirir en el país todas las especies que componen el vestuario y equipo de las tropas, existiendo el firme propósito de llegar a obtener su total elaboración en Chile" ${ }^{22}$. En fin, el fo m e n to de la industria nacional se debía impulsar también, además de por otra serie de mecanismos como bonificaciones y primas de exportación ${ }^{93}$, por las facilidades que se les darían a través del crédito, con la creación de una serie de "Cajas de Crédito" 94.

Desde otra perspectiva, se priorizaba el desarrollo de una "política de nacionalización de la producción, tratando de librar al país del tributo que paga al extranjero por artículos de primera necesidad"95, por lo que, por ejemplo, se impulsaría el cultivo de la betarraga azucarera para reemplazar a la azúcar de caña ${ }^{96}$. Y se llegaría a postular y hasta a concretar la "nacionalización" de ciertos rubros económicos. Por ejemplo, se anunciaría "la nacionalización de la producción de energía eléctrica" ${ }^{” 7}$ y se concretaría -en lo inmediato- la de los seguros ${ }^{98}$.

86 El Mercurio (29 agosto 1927), p. 3.

87 El Diario Ilustrado (8 julio 1927), p. 13.

${ }^{88}$ El Diario Ilustrado (25 agosto 1927), p. 7.

89 El Diario Ilustrado (26 agosto 1927), p. 7

90 El Diario Ilustrado (13 enero 1928), p. 5.

${ }^{91}$ El Diario Ilustrado (17 julio 1927), p. 23.

${ }^{2}$ Mensaje, cit. (n. 78), p. 27.

93 "La prima a los productores de salitre que usen carbón nacional", titulaba El Diario Ilustrado (13 septiembre 1927), p. 7; "Prima a las naves nacionales que transporten salitre”, El Diario Ilustrado (17 septiembre 1927), p. 9.

${ }^{94}$ Cfr. Bernedo, Patricio, cit. (n. 8), pp. 63 ss.

95 Mensaje, cit. (n. 78), p. 35.

96 El Mercurio (30 abril 1927), p. 3 y El Diario Ilustrado (9 septiembre 1927), p. 9.

${ }^{7}$ El Mercurio (26 abril 1927), p. 3, discurso del Ministro del Interior.

${ }^{9}$ La Nación (14 septiembre 1927), p. 5. Cfr. El Diario Ilustrado (19 julio1927), p. 7. 


\section{LA DEFENSA CONSERVADORA DEL RÉGIMEN LIBERAL-}

PARLAMENTARIO

Sobreponiéndose al ambiente que se vivía -se ha solido caracterizar el período como la d i c t a d u ra d e I bá ñ e z ${ }^{99}$ - el Partido Conservador mantendría una actitud crítica ante el gobierno y las reformas que impulsaba. Ello resulta evidente con sólo consultar las páginas de El Diario Ilustrado, órgano representativo de la dirigencia santiaguina del partido -sin perjuicio de que en él hubiera también otras corrientes, que sostenían opiniones más cercanas a las del gobierno ${ }^{100}-\mathrm{y}$ esto pese a que el periódico sufriría muchas veces la censura del gobierno y había tenido que aceptar la deportación de su director y también diputado del partido, Rafael Agustín Gumucio ${ }^{101}$.

De antología serían las columnas de Jenaro Prieto. Por ejemplo, apenas asumió el ministerio de los h o $\mathrm{m}$ b r e s $\mathrm{n}$ u e v o $s$, escribía, teniendo en cuenta que varios de los ministros no eran tan jóvenes ni noveles en cuestiones políticas: "Según entiendo, el calificativo de 'hombre nuevo' equivale a hombre sin práctica en los asuntos de Gobierno. Es como la condición de estudiante que puede mantenerse durante toda una vida, como es el caso del joven Larraín Neil, quien, si no me engañan los recuerdos, pronto celebrará sus bodas de oro con la Universidad"102. Unos días después escribía que había tenido la pesadilla de ser nombrado ministro de Agricultura y hablaba al respecto con su antecesor, de forma de dejar en evidencia la ignorancia que dominaría entre los ministros de Ibáñez: “¡Pero no sé una palabra! Tanto mejor. Así harás una política más nueva. ¿Qué voy a hacer? Sigue mi sistema. Haz declaraciones enérgicas y pregunta después de que se trata. Lo primero es resolver y lo segundo aprender" 103 .

A propósito de un decreto del gobierno en el que se anunciaba que se perseguiría la ociosidad, mostraba su preocupación, porque casi todos sus amigos estaban desocupados. "A unos los pilló la reorganización, a otros la crisis, a otros la reforma del reglamento de la Cámara”. Luego agregaba: "Santiago Watt no descubrió el vapor en un momento de trabajo, sino de la más absoluta desocupación, contemplando una tetera de agua hirviendo; Arquímedes hizo el mayor de sus inventos en el baño; Franklin encumbrando volantines, y Newton mientras sesteaba a la sombra de un manzano [...] Todos estos individuos deberían haber caído presos por desocupados y no digo nada de Beethoven, Mozart, Chopin, etc. que no hicieron otra cosa que meter ruido después de las 11 de la noche [...] Por fortuna aquí en el país, no hay peligro alguno de que entre los desocupados vaya a caer algún hombre de genio"104.

La Constitución Política de 1925 se había aprobado contra la opinión del

\footnotetext{
99 Vial, Gonzalo, Historia, Volumen IV, (n. 3).

100 Brahm García, Enrique, La Unión, cit. (n. 9) y Brahm García, Enrique, El Partido Conservador, cit. (n. 9).

101 El Diario Ilustrado (11 febrero 1927), p. 3.

102 El Diario Ilustrado (12 febrero 1927), p. 3. "Carta a un hombre nuevo".

103 El Diario Ilustrado (19 febrero 1927), p. 5. "Una noche de Ministro".

${ }^{104}$ El Diario Ilustrado (9 febrero 1928), p. 3. "No más ociosos".
} 
Partido Conservador ${ }^{105}$, por lo que no puede sorprender que durante los primeros años del gobierno de Ibáñez fueran una constante las críticas al texto constitucional vigente. Se cuestionaba, por ejemplo, la dieta parlamentaria, introducida por "la Constitución 'impuesta', y en cuantía que no cuadra con un país modesto como el nuestro. No había dieta cuando las finanzas nacionales eran prósperas, y viene a establecerse, y elevada, en pleno régimen de déficit incorregibles" ${ }^{106}$. Se solía recordar que la Constitución de 1925 no había nacido "en condiciones normales, aunque después, por consenso general se considere aceptada plenamente" ${ }^{107}$.

Naturalmente se consideraba que la nueva Constitución daba al presidente de la República "facultades excesivas para un país de organización unitaria como el nuestro"108. "Sus facultades son enormes", se agregaba en otro lugar ${ }^{109}$. Por lo demás, ello se veía reflejado también en la práctica, desde el momento en que "lo evidente ahora es que la parte del Gobierno en la formación de las leyes ha sido predominante en alto grado" 110 .

Más de fondo era la crítica dirigida a la relación de los ministros con el presidente de la República. Luego de recordarse por el editorialista de El Diario Ilustrado que la gran crítica que se hacía al régimen parlamentario era la constante rotativa ministerial, hacía ver que con "la Constitución nueva, la que hemos solido llamar 'impuesta', precisamente para concluir con el daño de la inestabilidad ministerial", durante los primeros meses de su vigencia, "continuamos viendo los mismos cambios ministeriales que antes. Ayer ha ocurrido uno nuevo [...] Los ministerios se modifican o renuevan con la misma frecuencia que antes, cada tres meses o poco más". Lo más grave, en opinión del periódico, era que detrás de los cambios no estaban ni el Congreso, ni los partidos, como ocurría durante el régimen parlamentario; pero tampoco el presidente de la República. Habría “otras fuerzas que los provocan, como lo han provocado ayer: son grupos de civiles que no forman partido, sin responsabilidad, que obran ocultamente, y logran interesar a algunos elementos militares. Estos cambios de gobierno impuestos al presidente de la República, aunque se salven o disimulen las apariencias, [...] son abiertamente inconstitucionales; no se respeta de verdad la nueva Constitución" ${ }^{111}$. Además, parecían mantenerse las formas parlamentarias. "El Presidente ha llamado a un político -en este caso, un militar-, para que organice Ministerio. No ha sido S.E. quien haya escogido individualmente a sus nuevos Secretarios de Estado"112. En todo caso se reconocía que en un régimen presidencial los cambios ministeriales tenían menos importancia que en el parlamentario. "En este el gobierno mismo cambia; en aquel un mismo gobierno permanece" 113 .

\footnotetext{
105 Brahm García, Enrique, El Partido Conservador, cit. (n. 9).

106 El Diario Ilustrado (27 enero 1927), p. 3.

${ }_{107}$ El Diario Ilustrado (30 mayo 1928), p. 3.

108 El Diario Ilustrado (8 mayo 1927), p. 7.

109 El Diario Ilustrado (8 abril 1927), p. 3.

110 El Diario Ilustrado (10 febrero1929), p. 3.

111 El Diario Ilustrado (10 febrero1927), p. 3.

112 El Diario Ilustrado (12 febrero 1927), p. 3.

113 El Diario Ilustrado (20 noviembre 1927), p. 11.
} 
Por otra parte, aunque por las características de los primeros presidentes que gobernaron el país luego de la entrada en vigencia de la nueva Constitución, ello no se había hecho plenamente evidente, no correspondía ahora que los Ministros tuvieran una presencia tan constante en el Congreso Nacional, pues en lo político, no dependían de las mayorías dominantes en las cámaras. Ello sin perjuicio de que de una u otra forma debían tener contacto con los parlamentarios y sus partidos para conseguir la aprobación de las leyes ${ }^{114}$.

También defendía El Diario Ilustrado la descentralización del país -recordaba al efecto lo norma sobre las Asambleas Provinciales contenida en la Constitucióncriticando el hecho de que el gobierno hubiera designado directamente a las nuevas autoridades comunales. Si había un ámbito en el que la democracia debía hacerse plenamente efectiva era el municipal ${ }^{115}$.

En materias electorales los conservadores se lamentaban de que, pese a existir el sufragio universal masculino en Chile, el número de ciudadanos inscritos no alcanzaba ni a la mitad de los posibles ${ }^{116}$. Además de ellos había un número importante que no participaba en las elecciones, pese al hecho de que desde hacía un par de años un D.L. había introducido el voto obligatorio, estableciendo sanciones penales para los infractores ${ }^{117}$. En cambio, la inscripción en los registros no era obligatoria. Frente a ello los conservadores eran partidarios de extender la voluntariedad también al ejercicio del sufragio ${ }^{118}$.

Dentro de lo que se podía, El Diario Ilustrado sería muy crítico de las acciones del gobierno que se salían del marco constitucional y legal. Los conservadores no habían sido partidarios de la nueva Constitución, pero preferían la plena vigencia de sus normas al dominio de la arbitrariedad. Así es cómo protestarían por la detención de Rafael Luis Gumucio y de otra serie de políticos ${ }^{119}$ y por la censura de prensa $^{120}$. No manifestaban una oposición cerrada a la a c c i ón de p u radora emprendida por el gobierno de Ibáñez, pero hacían ver que todo podía hacerse "sin salirse de la Constitución -la antigua o la nueva- y de las leyes. Será más lento el método, pero menos sujeto a ligerezas, errores e injusticias; de caracteres de mayor autoridad y permanencia; más seguramente educador y ejemplificador. Y, sobre todo, no hay verdaderas autoridades más allá de la Constitución y las leyes" ${ }^{\prime 21}$. Desde otra perspectiva y en otras circunstancias hacían ver que era "un error evidente suponer que no puede haber gobiernos fuertes dentro de marcos constitucionales" ${ }^{\prime 22}$. Incluso llegaban a cuestionar la doctrina que defendía la

114 El Diario Ilustrado (7 junio 1927), p. 3.

115 El Diario Ilustrado (5 enero 1928), p. 3 y (20 junio 1927), p. 3.

116 El Diario Ilustrado (20 abril 1928), p. 3.

117 El Diario Ilustrado (7 junio 1928), p. 3. "Ha sido ciertamente una anomalía curiosa que el voto obligatorio, con sanciones penales, haya sido impuesto por un decreto ley, es decir, por una actividad extra constitucional", sin que mediara el sufragio universal.

118 El Diario Ilustrado (6 junio 1928), p. 3 y (18 agosto 1928), p. 3.

119 El Diario Ilustrado (24 febrero 1927), p. 3.

120 El Diario Ilustrado (25 febrero 1927), p. 3. "Por imposibilidad de expresar nuestra opinión, debemos abstenernos de todo comentario sobre los sucesos de ayer".

121 El Diario Ilustrado (24 marzo 1927), p. 5.

${ }^{122}$ El Diario Ilustrado (12 julio 1928), p. 3. 
posibilidad de que pudieran suspenderse las garantías constitucionales en caso de necesidad y para salvaguardar el orden público ${ }^{123}$.

En su momento se tuvo la esperanza de que la elección presidencial que llevó al gobierno a Carlos Ibáñez del Campo -aunque no necesariamente les gustara el candidato- sería el momento adecuado para recuperar definitivamente la normalidad constitucional ${ }^{124}$. "Después de una situación anómala -se señalaba en un editorial del órgano conservador- que se ha prolongado demasiado, [...] entraremos en pleno régimen constitucional y legal. El hecho de encontrarse el poder legislativo en funciones, contribuirá a robustecer la confianza del país en que tal régimen sea escrupulosamente observado. También el hecho de que, después de las elecciones de mañana, tendremos un nuevo $\mathrm{p}$ residente constitucional en la persona del señor coronel Ibáñez"125. Y expresiones similares se volverían a repetir al momento de asumir Ibáñez -formalmente- la primera magistratura del país ${ }^{126}$.

No es que les pareciera bien que fuera Ibáñez, ni menos que se tratara de un militar, pero por lo menos se trataba de un presidente constitucional que iba a gobernar acompañado de un congreso, de acuerdo a la carta de 1925. De hecho, a propósito de algún movimiento militar posterior, desde el Ilustrado se destacaba que el Ejecutivo hacía muy bien "en apartar definitivamente las fuerzas armadas de toda injerencia en el Gobierno. Ha existido cierta tolerancia desde el año 1924, que no debe continuar. En este punto -como en todo- deben respetarse escrupulosamente las prescripciones constitucionales"127. Y en vista de que pasaba el tiempo y la normalidad constitucional no parecía volver en plenitud, con Ibáñez ejerciendo un poder que iba más allá de lo establecido en el texto constitucional para el presidente de la República, el editorialista de El Diario Ilustrado, le ponía el ejemplo de lo que había ocurrido en Ecuador, donde la figura dictatorial que gobernaba ese país sudamericano había decidido restablecer el régimen constitucional, llamando a elecciones para elegir por sufragio universal una asamblea constituyente que debía dar forma a una nueva carta. Además, se hacía ver el contraste con Chile, donde la Constitución de 1925 había sido obra de una comisión nombrada por el ejecutivo ${ }^{128}$.

Aun cuando se insistiera en la necesidad de volver al orden constitucional, el ideal de los conservadores seguía siendo el régimen parlamentario, practicado de acuerdo a las normas de la constitución anterior -la de 1833- y no el de la consti-

${ }^{123}$ El Diario Ilustrado (6 octubre 1928), p. 3.

${ }^{124}$ El Diario Ilustrado (22 mayo 1927), p. 9. "[...] la esperada vuelta a la normalidad institucional y legal”. De (24 mayo 1927), p. 3. “[...] volver definitiva y enteramente a la normalidad constitucional”. De (8 junio 1927), p. 3. "La entera normalidad constitucional y legal, valdrá por una seguridad para el trabajo de toda la nación”.

125 El Diario Ilustrado (21 mayo 1927), p. 3.

126 El Diario Ilustrado (12 julio1927), p. 3. "Esperamos que la proclamación presidencial del Excmo. Señor Ibáñez signifique un paso que nos conduzca a la definitiva normalidad constitucional y legal, la cual no se opone absolutamente, sino al contrario, a la tranquilidad necesaria para el trabajo, a las antiguas normas de severidad y corrección en la administración [...]”.

${ }^{127}$ El Diario Ilustrado (7 julio 1927), p. 7.

${ }^{128}$ El Diario Ilustrado (12 julio 1928), p. 3. "Vuelta a un régimen constitucional en el Ecuador". 
tución vigente. De esta forma los problemas manifestados en el funcionamiento del régimen de gobierno tras la entrada en vigencia del texto de 1925, tanto durante el gobierno de Figueroa como en el de Ibáñez, se explicarían porque "la fragilidad de la nueva constitución es consecuencia lógica del abandono de la constitución antigua por los mismos obligados a cumplirla y a hacerla cumplir. Se le atribuían defectos inexistentes; se desatendían los métodos legítimos de reforma; se desoían los ofrecimientos de arreglos, posibles e inmediatos para corregir la inestabilidad ministerial", que habría sido el único problema real del sistema ${ }^{129}$.

Más allá de los problemas que habrían afectado a algunos regímenes parlamentarios concretos, como el chileno y también europeos (Italia y España), su funcionamiento en Inglaterra sería la demostración de su intrínseca calidad. "El parlamentarismo es un método, su buen éxito o fracaso depende de los hombres encargados de aplicarlo, pero tiene el mérito de ser la mejor organización política para que un pueblo conserve sus libertades. Entre el despotismo y la anarquía nada hay como una asamblea deliberante" ${ }^{130}$. En concreto los problemas del parlamentarismo en Chile habrían sido solo consecuencia, en lo fundamental, de los abusos cometidos en el ejercicio del sufragio universal (intervención de las autoridades, cohecho, etc.) y no eran inherentes al sistema mismo ${ }^{131}$. No es casualidad que fuera "el sistema dominante en la mayor parte de los países bien constituidos"132.

El Diario Ilustrado se dedicaría también a defender, contra los constantes ataques del gobierno, el sistema de partidos en general y al Partido Conservador en particular. Para ello destacaría la cooperación que estaban prestando los partidos tradicionales a las reformas que impulsaban Ibáñez y su círculo. "Nunca como ahora -se afirmaba en un artículo editorial- los partidos han desarrollado una actividad más provechosa, más eficaz y más patriótica en favor de los intereses nacionales" 133 . En un tono semejante se expresaría la Junta Ejecutiva del Partido Conservador en una declaración pública dónde, entre otras cosas, señalaba que "son injustos los cargos hechos al parlamento actual, que ha dado su más leal y eficiente cooperación de trabajo a todos los gobiernos en cualquiera obra de bien nacional, olvidando patrióticamente los ataques de que ha sido víctima en más de una ocasión de parte de alguno de los propios ministros" ${ }^{134}$. Se recordaba también, y se notaba aquí el sesgo conservador y anti alessandrista, que hasta el año 1920 no habría habido mayores quejas contra los partidos, por lo menos en el ámbito financiero. "Después se multiplicaron y agravaron los errores, pero, sinceramente, no alcanzaron el grado desmedido que el año 1925, época en que los gobiernos

129 El Diario Ilustrado (8 mayo 1927), p. 7.

130 El Diario Ilustrado (30 agosto 1928), p. 3.

131 El Diario Ilustrado (16 agosto 1928), p. 3.

132 El Diario Ilustrado (24 noviembre 1927), p. 7.

133 El Diario Ilustrado (9 febrero 1927), p. 5. "En su deseo de facilitarle al Gobierno -agregaba- todos los medios de equilibrar la hacienda pública, las dos cámaras despacharon en el espacio de unos cuantos días una ley que arma al Ejecutivo de facultades realmente extraordinarias, restringiendo las atribuciones propias del parlamento y manifestando así la más amplia confianza en todos y cada uno de los Ministros de Estado, que son ahora los árbitros de la situación”. Cfr. El Diario Ilustrado (18 febrero 1927), p. 5.

${ }^{134}$ El Diario Ilustrado (23 febrero 1927), p. 3. 
'de facto' se mantuvieron a distancia de los partidos políticos”135. Por lo demás la prensa conservadora se encargaría de recordar los grandes aportes que había hecho el Partido Conservador al país a lo largo de su historia. Así habría sido un gran impulsor y defensor de la libertad electoral, de las leyes sociales, un enemigo declarado de la inmoralidad administrativa, etc. ${ }^{136}$.

Frente a la postura ibañista de gobernar al margen o por encima de los partidos, los conservadores defenderían siempre la necesidad de su existencia. "La política y los partidos políticos han existido e existirán siempre -se señalaba en El Diario Ilustrado-; imaginarse lo contrario es una pura ilusión"137. Mientras que en otro artículo editorial se insistía en recordar que "los partidos son un hecho políticosocial: difícilmente se concibe un país sin ellos: son la base de los gobiernos en las principales naciones y se les ve vivir e influir en los negocios públicos, ya en regímenes de gobierno parlamentarios, ya en presidenciales" ${ }^{138}$. Resultaba natural que, en todos los países, más allá de la forma de gobierno que tuvieran, grupos de ciudadanos tendieran a unirse de acuerdo a sus ideas, intereses, aspiraciones y otros elementos que tuvieran en común, para así dar mayor fuerza a sus pretensiones. "Para que en una nación no existieran partidos políticos -apuntaba el Ilustrado- sería menester que todos sus miembros tuvieran las mismas ideas, los mismos intereses, las mismas aspiraciones. Como esto es imposible, los partidos políticos deberán existir siempre en los países de régimen representativo"139. Más todavía, en la práctica, en todas las grandes democracias de occidente funcionaban sistemas de partidos. De momento la única excepción parecía ser la Italia de Mussolini en la que se probaba un sistema nuevo -congreso de base gremial-, pero todavía se estaba muy lejos de saberse cuál iba a ser el resultado de ese experimento, considerando que se trataba de un régimen que había terminado con la libertad de prensa ${ }^{140}$.

Ibáñez no sólo gobernaría al margen o por encima de los partidos, sino que durante su mandato habría quienes postularían su reemplazo por las corporaciones. En la práctica, nunca se avanzaría mucho en esa dirección y es una idea que nunca se concretaría, pero fue un argumento recurrente de la crítica anti partidaria. La dirigencia conservadora y su principal medio de prensa, El Diario Ilustrado, se opondrían de manera absoluta a esa propuesta. Como argumento de fondo consideraban insostenible que la representación tuviera por base "los intereses económicos de las fuerzas vivas de la nación”, dejando de lado las cuestiones morales y de alta política que eran de mucho mayor importancia. Por otra parte, desde un punto de vista formal, no parecía fácil dar forma a la representación gremial. ¿Qué representación se daría a cada gremio? ¿La representación estaría en proporción al número de miembros de cada gremio? "En tal caso, los gremios

135 El Diario Ilustrado (18 mayo 1927), p. 3.

136 El Diario Ilustrado (15 abril 1928), p. 9. "La obra del partido Conservador. Ataque injustificado".

137 El Diario Ilustrado (19 febrero 1927), p. 5.

138 El Diario Ilustrado (18 mayo 1927), p. 3.

139 El Diario Ilustrado (20 junio 1928), p. 3.

${ }^{140}$ El Diario Ilustrado (21 agosto 1928), p. 3. 
obreros, que son los más numerosos y a la vez los menos preparados, tendrían la mayor representación en el Congreso y a ellos quedaría entregada la labor legislativa y fiscalizadora”. Además, en un parlamento de esa naturaleza terminarían sólo por enfrentarse violentamente los gremios capitalistas contra los de asalariados. "En verdad, se concluía en El Diario Ilustrado, cuando se analizan todas las dificultades que surgen de la aplicación del sistema de representación gremial; cuando se consideran todos los peligros que él envuelve y cuando se observan los insignificantes resultados que ofrece, se llega al convencimiento de que es prudente esperar los resultados que dé este sistema una vez que el haya sido puesto en práctica en los países que se proponen ensayarlo"141.

Alguna coincidencia con la posición del gobierno de Ibáñez es posible encontrar en relación a la actitud que se tiene frente al gobierno de Mussolini, del que se alaban algunos aspectos, por ejemplo, su oposición a ciertos principios fundantes de la Revolución Francesa ${ }^{142}$. Sin embargo, se adopta por El Diario Ilustrado una posición crítica frente al creciente autoritarismo de que empezaba a hacer gala el gobierno fascista: preeminencia del Fascismo con Mussolini a la cabeza ${ }^{143}$.

En lo que había plena coincidencia con el gobierno de Carlos Ibáñez, era en la común oposición a la amenaza comunista. Durante los años 1927 y 1928 fue una constante de El Diario Ilustrado la publicación de artículos denunciando los crímenes del comunismo y la amenaza que esa doctrina representaba para el mundo libre ${ }^{144}$. Ni siquiera aparecía posible mantener relaciones comerciales con un régimen como el soviético, ni menos reconocerlo diplomáticamente ${ }^{145}$. "El peligro bolchevista es formidable, se señalaba en El Diario Ilustrado. El bolchevismo trabaja con grandísimo afán para alcanzar prosélitos y usa para extenderse de todos los medios que conoce la propaganda en los tiempos que corren. El bolchevismo aspira a ejercer dominio en el mundo entero; sus emisarios recorren todos los países y sus doctrinas se van infiltrando paulatinamente tanto en las aulas como en los centros sindicalistas" 146 .

\section{EN DEFENSA DEL LIBERALISMO ECONÓMICO}

También en el ámbito de las políticas económicas la dirigencia del partido Conservador y su órgano más representativo, El Diario Ilustrado, se atreverían a ir en contra de los postulados defendidos y puestos en práctica por el gobierno de Carlos Ibáñez del Campo y de las ideas económicas en que se sustentaban y que estaban destinados a dar su impronta a la economía chilena hasta bien entrado el siglo XX.

En efecto, todavía durante los años 1927 y 1928, El Diario Ilustrado, sin

${ }^{141}$ El Diario Ilustrado (31 julio 1928), p. 3. Cfr. El Diario Ilustrado (16 enero 1928), p. 3.

142 El Diario Ilustrado (14 abril 1927), p. 3.

143 El Diario Ilustrado (11 septiembre 1928), p. 3 y (23 septiembre 1928), p. 9.

144 El Diario Ilustrado (17 enero 1927), p. 5, (9 febrero 1927), p. 3, (29 marzo 1927), p.

3, (13 abril 1927), p. 3, (25 abril 1927), p. 3, (20 febrero 1928), p. 3.

${ }_{145}$ El Diario Ilustrado (8 octubre 1928), p. 3.

146 El Diario Ilustrado (2 junio 1928), p. 3. 
perjuicio de su identificación con la doctrina social de la Iglesia y de resaltar como antes se ha señalado- el papel que le había cabido al Partido Conservador en la aprobación de las leyes sociales sería el gran defensor de los principios del liberalismo clásico frente al creciente intervencionismo estatal que parecía ser la tendencia dominante tanto en Chile como en el mundo. "La tendencia actual es entregarlo todo al Estado -se señalaba en un artículo editorial-, como si el progreso económico pudiera sólo venir de él. Y los gobiernos yerran mucho, por falta de estudio de las obras que emprenden"147. Se recordaba, en contraste, que "antes se confiaba más en el mundo en las soluciones de libertad"148. A propósito de la política salitrera del gobierno en el mismo medio se señalaba: "Preferiríamos el antiguo papel del Gobierno, de menos paternalismo o estatismo, que dejaba a las empresas productoras en mayor libertad, con todas sus iniciativas y responsabilidades de aciertos y fracasos"149. Desde otra perspectiva se afirmaba con convicción que "el gobierno podrá pensar en leyes de protección, en una intervención más o menos directa en algunas de nuestras principales industrias: pero la última palabra la dicen los mercados, frente a los productos competidores"150. El apoyo del Estado a los privados debía ser sólo indirecto, por la vía de disminuir los gravámenes que recaían sobre sus capitales y a través de la inversión en infraestructura con lo que se facilitaba y se veía favorecida la actividad económica ${ }^{151}$.

De esta forma se reaccionaba contra la tendencia dominante a partir de la intervención militar de septiembre de 1924 que tendía a hacer del Estado un ente todopoderoso. De hecho, la legislación aprobada por los gobiernos de facto sería objeto de constantes críticas, sobre todo desde el momento en que -más allá de su necesidad o justicia-imponían una carga excesiva a los privados. Como bien se sabe, uno de los primeros efectos del $\mathrm{r} u$ id o d e s a bles fue la aprobación de un paquete de leyes sociales el 8 de septiembre de $1924^{152}$, las que no habrían sido suficientemente estudiadas ${ }^{153}$. "El error fundamental de nuestra legislación social, señalaba el editorialista de El Diario Ilustrado, es haber dictado todas las leyes de un solo golpe, coincidiendo su aplicación, que envolvía gravámenes onerosos con la dictación de nuevos impuestos y el aumento de las contribuciones existentes" ${ }^{154}$. No se proponía la derogación de las leyes sociales, sino que de lo que se trataba era de "quitar de ellas todo lo exagerado o excesivamente oneroso, en tal forma que comprometa la existencia misma de la explotación" ${ }^{155}$. Ello se hacía tanto más necesario por la situación de crisis en la que se encontraba la economía nacional ${ }^{156}$. Más todavía, se destacaba que mientras la economía nacional se veía débil y no lograba despegar, el Fisco había "aumentado sus disponibilidades”. Ello

${ }^{147}$ El Diario Ilustrado (30 enero 1928), p. 3.

148 El Diario Ilustrado (6 septiembre 1927), p. 3.

${ }_{149}$ El Diario Ilustrado (26 mayo 1928), p. 3.

150 El Diario Ilustrado (26 junio1927), p. 3.

151 El Diario Ilustrado (13 octubre 1927), p. 3.

152 Vial Correa, Gonzalo, Historia de Chile, Vol. III, cit., (n. 1), pp. 393 ss.

153 El Diario Ilustrado (22 septiembre 1928), p. 3.

${ }_{154}$ El Diario Ilustrado (23 septiembre 1928), p. 3.

155 El Diario Ilustrado (3 mayo1928), p. 3.

156 El Diario Ilustrado (27 agosto 1927), p. 3. 
se explicaría porque aparecían como exagerados no sólo gastos derivados de las leyes sociales, sino también, el monto que personas y empresas debían pagar en impuestos y en tarifas ferroviarias ${ }^{157}$. A todo ello se agregaría el creciente valor de las primas de seguros y los efectos esperables de la entrada en vigencia del nuevo arancel aduanero, cuyo efecto inmediato sería el encarecimiento de una serie de productos, con los consiguientes problemas para el comercio y para ciertas industrias ${ }^{158}$.

El órgano conservador se manifestaría también como un decidido defensor del derecho de propiedad privada, el que también se veía amagado en sus alcances por la legislación intervencionista en lo económica impulsada por el gobierno de Carlos Ibáñez. Pese a que -según ya se ha señalado-en una de las pocas cuestiones en que los conservadores coincidían con las políticas ibañistas era en su común oposición al comunismo, se manifestarían ciertas aprehensiones frente a políticas del gobierno que parecían acercarse a propuestas propias de esa ideología. "Por ejemplo, se señalaba en un artículo de El Diario Ilustrado titulado Proyecciones del comunismo, la cláusula introducida en el proyecto de creación de la Superintendencia del Salitre, por la cual se autoriza al Ejecutivo para expropiar todas las salitreras, idea inspirada sin duda en el tan ansiado propósito de nacionalizar la industria y ponerla al margen de las especulaciones del capital extranjero, puede aparecer a los ojos de los que miren este proyecto desde Europa, como un paso en el sentido de la socialización de la industria"159.

Más decidida sería todavía la oposición conservadora a las amplísimas facultades que en materia de expropiaciones de terrenos agrícolas se concedían al estado en el proyecto de ley de colonización agrícola que terminaría por hacer aprobar el gobierno de Carlos Ibáñez. Estaba en juego en este caso la propiedad de la tierra, base del poder económico de buena parte de la dirigencia y bases del Partido Conservador. Además, los conservadores parecían darse cuenta de que, si se cedía en estas materias y no se salía en defensa del derecho de propiedad, ello podía ser sólo el comienzo de un proceso que desembocara -como de hecho terminó por ocurrir- en un programa mucho más radical de reforma agraria. Objeto de las críticas lo sería, en lo fundamental, el art. segundo del proyecto de ley en el que se señalaba que para la formación de colonias agrícolas se podrían expropiar por el estado "los terrenos que se requieran" en las zonas de colonización que al efecto "se determinen" de acuerdo con los proyectos que "apruebe el presidente de la República, a propuesta de la Caja de Colonización Agrícola”. Fuera de algunas pequeñas excepciones que contemplaba el proyecto, "puede decirse que toda la propiedad agrícola del país quedará en el evento de una posible expropiación. Tal eventualidad dista mucho de ser un estímulo para la producción nacional” ${ }^{160}$. Más todavía, recurrir a la expropiación - “recurso absolutamente excepcional”-cuando

${ }_{157}$ El Diario Ilustrado (2 enero 1928), p. 3. Cfr. El Diario Ilustrado (11 octubre 1927), p. 3, (12 enero 1928), p. 3, (9 agosto 1928), p. 3.

158 El Diario Ilustrado (6 mayo 1928), p. 11.

159 El Diario Ilustrado (1 junio 1927), p. 3. En el mismo editorial se consideraba como “comunista” la propuesta de establecer la "escuela común obligatoria".

${ }^{160}$ El Diario Ilustrado (13 julio 1928), p. 3. Cfr. El Diario Ilustrado (19 agosto 1928), p. 15. 
había otros medios más respetuosos del derecho de propiedad para conseguir los terrenos que se necesitaban, parecía algo fuera de lugar ${ }^{161}$. Al respecto tampoco tendría sentido argumentar que se expropiarían sólo fundos abandonados o mal trabajados, porque "no creemos - decía el editorialista de El Diario Ilustrado-que en condiciones de cierta generalidad se pueda hacer a nuestros agricultores el cargo de tener en relativo abandono sus tierras" ${ }^{\prime 62}$. Ni siquiera se aceptaba la existencia de grandes $\mathrm{l}$ a t i f u n d i o $s$, porque habría estado operando de forma constante la subdivisión de la propiedad por razones hereditarias ${ }^{163}$. Los conservadores, por lo menos aquel sector del partido que se expresaba a través de El Diario Ilustrado, oponían a las reformas impulsadas por el gobierno de Ibáñez y que marcarían la tendencia en las próximas décadas de la historia de Chile, el concepto tradicional de propiedad privada contenido en el Código Civil. "No vamos a hablar de la teoría del derecho de propiedad, función social; no está incorporado en la nueva constitución; ni cambia el punto de que se trata"164.

Los conservadores opondrían también los grandes principios de la economía clásica liberal a las tendencias nacionalistas y proteccionistas propiciadas por el gobierno de Carlos Ibáñez. Con su característico sentido del humor, se burlaba Jenaro Prieto de ese nacionalismo, a propósito del hecho de que se había acordado de que los nuevos bancos de la plaza de armas serían "de pino araucaria y la pintura de color roble americano vetado, de primera calidad y adecuada para toda intemperie". "Tendrían pues, un carácter absolutamente criollo en el fondo y totalmente norteamericano en la superficie”. Se criticaba así, subliminalmente, el nacionalismo económico del gobierno. Burla que seguía con la referencia a los $\mathrm{n}$ a c i o $\mathrm{n}$ a $\mathrm{l}$ i s t a s ministros, cuyos apellidos, nada de chilenos, eran "Edwards, Blanche, Froeden y Koch"165.

Frente a la nacionalización del negocio de los seguros, se sostenía en El Diario Ilustrado, "nosotros habríamos preferido un régimen de libertad, con prohibición de acuerdos de tarifas o monopolios, con toda la reglamentación, medidas de seguridad y control que se creyeran convenientes: el servicio de seguros, según toda probabilidad, tendería a ser más barato por el efecto de una sana competencia que ya no podrá existir"166.

Los conservadores miraban también con desconfianza la tendencia creciente que se daba en Chile y en el mundo de subir los aranceles aduaneros para proteger la industria nacional. Un ejemplo muy preciso y representativo de las erradas políticas económicas del gobierno, sustentadas en un cierto nacionalismo, era el de la creación de la Aduana de Punta Arenas. El editorialista de El Diario Ilustrado hacía ver que mientras fue puerto franco, bullía en esa ciudad la actividad comercial, en cambio, una vez instalada la aduana, "el movimiento comercial se trasladó a Usuahia y la región argentina. Los estancieros dejaron de surtirse en

\footnotetext{
${ }^{161}$ El Diario Ilustrado (2 agosto 1928), p. 3.

162 El Diario Ilustrado (27 julio 1928), p. 3.

163 El Diario Ilustrado (22 julio 1928), p. 11.

164 El Diario Ilustrado (13 julio 1928), p. 3.

165 El Diario Ilustrado (9 julio 1928), p. 8.

166 El Diario Ilustrado (3 julio 1928), p. 3.
} 
Punta Arenas, y se surten ahora de Bahía Blanca y del mismo Buenos Aires"167. Siempre se mostraría partidario de moderar el proteccionismo para facilitar la libre circulación de las mercaderías y propiciar que se diera una cierta especialización de la producción derivadas de las ventajas comparativas de que gozaran los distintos países. "Que nosotros no nos empeñemos demasiado en fabricar azúcar, por ejemplo, ni otros países tropicales o semi-tropicales en sembrar trigo" 168 . De lo contrario lo único que se conseguía era el aumento de los precios con el consiguiente perjuicio para los sectores más desposeídos de la sociedad ${ }^{169}$. Con el objetivo aparentemente beneficioso para el país - "nacionalista"- de "proteger la industria nacional" a través de un nuevo arancel aduanero, lo que se hacía en realidad era aumentar los costos de una serie de productos para el común de los ciudadanos ${ }^{170}$. Por ejemplo, a propósito del establecimiento de un gravamen aduanero sobre los abonos fosfatados, el editorialista de El Diario Ilustrado sostenía que "son las buenas doctrinas económicas las que defienden los intereses nacionales ligados al salitre" y no el proteccionismo ${ }^{171}$. Y si se trataba de apoyar a una industria nacional -por ejemplo, la del carbón- parecía mejor hacerlo a través de medios indirectos: buenos puertos, tarifas ferroviarias más bajas, facilidades de crédito, etc. ${ }^{172}$ y no vía aranceles.

Otra forma de protección clásica en Chile y que también defendía el gobierno ibañista, era la de reservar el cabotaje nacional a los buques chilenos, medida que según los conservadores tampoco habría traído los beneficios esperados, y parecía mucho mejor para el país establecer también en estas materias la libre competencia ${ }^{173}$. En el mismo ámbito, el editorialista de El Diario Ilustrado criticaba también el proyecto del Ejecutivo que establecía una subvención de un par de millones en beneficio de las compañías de navegación que hubieran mantenido un servicio regular de navegación interoceánico a través del Estrecho de Magallanes. El problema de esta subvención como de otras que había establecido el gobierno es que requerían ser financiadas con nuevos impuestos, con lo que se volvía a gravar a los comerciantes e industriales chilenos e indirectamente al

${ }^{167}$ El Diario Ilustrado (31 agosto 1927), p. 3.

168 El Diario Ilustrado (18 diciembre 1927), p. 9.

169 El Diario Ilustrado (15 agosto 1928), p. 3. "Las clases sociales más modestas, las más numerosas, vendrían a pagar en último término la mayor parte de la protección a la industria frutícola, que estará en manos de clases sociales más acomodadas”.

170 El Diario Ilustrado (6 mayo 1928), p. 11.

171 El Diario Ilustrado (27 enero 1928), p. 3.

172 El Diario Ilustrado (7 octubre 1927), p. 5 y (14 abril 1928), p. 3. La única defensa relativa del proteccionismo aparece en un artículo firmado por Francisco Antonio Encina, titulado "La organización de nuestra política económica y comercial”, donde se señalaba: "El proteccionismo cerrado es tan torpe, como el librecambismo sistemático. Hay que proteger o estimular lo que tiene posibilidades más amplias y más fáciles dentro de las condiciones en que la naturaleza, el grado de desarrollo económico y la concurrencia de los demás pueblos, nos colocan”. El Diario Ilustrado (29 noviembre 1927), p. 3.

${ }^{173}$ El Diario Ilustrado (4 agosto 1928), p. 3. Cfr. El Diario Ilustrado (26 agosto 1927), p. 5. 
público general porque, como consecuencia de lo anterior, subirían los precios de las mercaderías importadas ${ }^{174}$.

En fin, en su defensa de la libre competencia y de los principios liberales en materia económica que estaban siendo pasados a llevar por las autoridades de gobierno, los conservadores también se manifestaban críticos de la existencia de monopolios o trusts y de las fijaciones de precios $^{175}$.

Los conservadores, a través de las páginas de El Diario Ilustrado, se mostraban particularmente críticos con el crecimiento constante que habría tenido el gasto estatal a partir de la intervención militar de 1924 y que estaría alcanzando cotas extremas durante el gobierno de Carlos Ibáñez. "No podemos seguir con el tren de gastos de la legislación anormal de 1925", se señalaba en un artículo editorial ${ }^{176}$. Se estimaba que, naturalmente, el gasto del estado debía crecer a medida que aumentaba la población y la renta nacional, pero con ese límite. En cambio, ahora el crecimiento descontrolado del gasto público dependía "de las ideas dominantes de intervención del Estado, nuevos servicios, legislación social, etc." ${ }^{177}$. Se criticaban así las políticas de cuño keynesiano aplicadas por el gobierno que expandían el gasto público, por ejemplo, a través de la ejecución de un ambicioso programa de obras públicas. Mientras el gobierno hablaba de que su política era $\mathrm{n}$ a c i o $\mathrm{n}$ a l i s t a, en la práctica se estaría hipotecando el futuro del país a través del endeudamiento externo, expediente al que se recurría para financiar el creciente gasto público. "Se habla ahora de política "nacionalista", se afirmaba en un artículo editorial de El Diario Ilustrado. "Muy bien. Que cesen los compromisos externos; y, sobre todo, que cesen las causas que los han traído y pueden continuar trayéndolos: los gastos desproporcionados con relación a las facultades nacionales [...] El más sincero y eficaz $\mathrm{n}$ a c i o $\mathrm{n}$ a $\mathrm{l}$ i s $\mathrm{m}$ o financiero, consiste ahora en la rigurosa economía de los gastos públicos"178. En cambio, sí debían crearse las condiciones para atraer la inversión extranjera.

En opinión del conservantismo, debía seguirse una política de gasto más prudente, aspirando a alcanzar presupuestos que no tuvieran déficit, que estuvieran equilibrados. "Basta pensar, se señalaba en El Diario Ilustrado, que las entradas de la nación no pueden tener aumentos de consideración, pues es manifiesta la pobreza que aflige al país y la inconveniencia de imponer nuevos tributos que sólo tendría por resultado aumentar esa pobreza y precipitar la fuga de los capitales que por su situación especial puedan huir" ${ }^{179}$. Y si los déficits, por las razones que fueran, resultaban inevitables, resultaba más conveniente recurrir al crédito interno que al externo, pero también estos debían quedar sujetos a la exigencia de que los recursos así obtenidos se emplearan en inversiones reproductivas ${ }^{180}$.

\footnotetext{
${ }^{174}$ El Diario Ilustrado (28 junio 1928), p. 3.

175 El Diario Ilustrado (4 septiembre 1928), p. 7 y (28 diciembre 1927.

El Diario Ilustrado (4 septiembre 1928), p. 7 y (28 diciembre 1927) p. 3.

${ }^{176}$ El Diario Ilustrado (21 agosto 1927), p. 11.

177 El Diario Ilustrado (20 agosto 1927), p. 3.

178 El Diario Ilustrado (13 febrero 1927), p. 9.

179 El Diario Ilustrado (24 mayo 1927), p. 3.

${ }^{180}$ El Diario Ilustrado (21 abril 1928), p. 3 y (27 abril 1928), p. 3.
} 
En palabras que resultarían premonitorias en consideración a los efectos que tendría en Chile la "Gran depresión" de 1929, se afirmaba en El Diario Ilustrado: "No puede contarse con la certidumbre de un gran aumento de la producción exportable; y pueden presentarse las dificultades económicas y monetarias de que ayer hablábamos. Mientras la corriente de empréstitos continúe, la situación aparecerá muy satisfactoria; después podrá cambiar el color del cristal con que se la mire. He ahí los motivos de nuestras frecuentes observaciones, sin más fines que recomendar una patriótica prudencia" ${ }^{181}$.

A la luz de todo lo que se ha señalado no puede llamar la atención el que los conservadores y El Diario Ilustrado se mostraran particularmente críticos con el expediente que había ideado el gobierno para alcanzar un equilibrio en el presupuesto nacional: la distinción entre un presupuesto ordinario y otro extraordinario. Esta sería una solución absolutamente falaz y sin sustento real; una mera fachada para ocultar el déficit y el recurso al endeudamiento externo ${ }^{182}$.

\section{Conclusión}

A partir del momento en el que Carlos Ibáñez del Campo asumió el Ministerio del Interior durante el gobierno de Emiliano Figueroa junto a su equipo de h o m b r es nu e vos, se inició en Chile un acelerado proceso de profundas reformas administrativas y económicas ${ }^{183}$ que marcarían la tendencia para los decenios centrales de la historia del siglo XX en Chile. Para impulsar esas transformaciones no sólo contó Ibáñez con las grandes atribuciones que concedía al Ejecutivo la Constitución Política de 1925, sino que fue más allá, actuando como un caudillo consciente de contar con el apoyo de la mayoría del país - no en vano había sido elegido presidente de la República con el $98 \%$ de los votos ${ }^{184}$ - y de las Fuerzas Armadas. De ahí que su gobierno haya podido ser calificado de d i c t a d u r a ${ }^{185}$, en la medida en que perseguiría a sus enemigos políticos y sometería a la prensa a una fuerte censura con herramientas que iban más allá de las contempladas en la constitución y las leyes.

En ese contexto llama la atención el hecho de que la dirigencia del Partido Conservador y su principal órgano de prensa, El Diario Ilustrado, durante los años 1927 y 1928 hayan podido mantener -con cierta prudencia y recaudos- una posición crítica contra las políticas impulsadas por el gobierno, tanto en el plano político como en el económico. Lo sorprendente no es tanto que el gobierno haya tolerado que fueran cuestionados aspectos centrales de su programa, pues bajo Ibáñez siempre hubo un cierto margen de libertad para la disidencia, sino el que los conservadores siguieran defendiendo soluciones políticos y económicas que iban en contra de las tendencias dominantes en su tiempo y que terminarían por hacer propias -incluso después de la caída de Ibáñez- las principales fuerzas

\footnotetext{
181 El Diario Ilustrado (9 septiembre1928), p. 9.

182 El Diario Ilustrado (7 enero 1928), p. 3, (20 enero de 1928), p. 3, (10 enero 1928), p. 3.

183 Góngora, Mario, cit. (n. 2), pp. 75 ss.

${ }^{184}$ La Nación y El Mercurio de 23 de mayo de 1927, p. 1.

185 VIAL, Gonzalo, Historia de Chile vol. IV, cit. (n. 3) y VICUÑA, Carlos, cit. (n. 3).
} 
políticas del país y los distintos gobiernos chilenos hasta comienzos de la década de 1970. En lo político, seguiría identificándose con la ya derogada Constitución Política de 1833 y defendiendo las bondades del régimen parlamentario y el sistema tradicional de partidos, en directa contradicción a los postulados del gobierno ibañista. Ello sin perjuicio de que en esa postura coincidiera con un sector importante de la dirigencia de los partidos tradicionales, aunque, a la larga, todos terminaron por defender el presidencialismo ${ }^{186}$.

Más llamativa todavía resulta, en cambio, su defensa de los principios del liberalismo económico clásico frente a las tendencias intervencionistas y proteccionistas de cuño keynesiano dominantes. Ello resulta tanto más notable si se considera que esas políticas económicas se impondrían sin contrapeso en las décadas siguientes y fueron promovidas y defendidas por gobiernos del más distinto signo y dejarían su impronta en la historia nacional hasta $1973^{187}$. Además, esta posición sustentada por la dirigencia conservadora y El Diario Ilustrado resulta sorprendente en un momento en el que la doctrina social de la Iglesia era recepcionada con fuerza en círculos importantes del Partido, sobre todo entre la juventud del mismo ${ }^{188}$.

No cabe duda que, por lo menos durante los años iniciales del gobierno de Ibáñez, la dirigencia del Partido Conservador y El Diario Ilustrado iban contra la corriente de las tendencias dominantes en la historia nacional del siglo XX.

\section{BiBLIOGRAFÍA}

Archivos

Archivo Donoso Ibáñez (ADI) (privado).

Archivo del Ministerio de Relaciones Exteriores de Alemania (PAAA).

Prensa

Acción

El Diario Ilustrado

El Mercurio

La Nación

Sucesos

186 Brahm, Bertelsen y AmunÁtegui, cit. (n. 2).

187 Brahm García, Enrique Propiedad sin libertad, cit. (n. 2).

188 Pereira, Teresa, El partido Conservador 1930-1965. Ideas, figuras y actitudes (Santiago, Fundación Mario Góngora, 1994); DíaZ Nieva, José, De la Falange Nacional a la Democracia Cristiana (Madrid, Universidad Nacional de Educación a Distancia, 2000); GARAY, Cristián, El Partido Conservador Chileno 1857-1966. Tendencias internas y conflictos doctrinarios (Madrid, Tesis Doctoral UNED, 2005, inédita). Cfr. FERmANDOIs, Joaquín, Abismo y cimiento. Las relaciones entre Chile y Estados Unidos: 1932-1938 (Santiago, Ediciones de la P. Universidad Católica de Chile, 1997), donde se destacan las ideas liberales en lo económico defendidas por el dirigente conservador Héctor Rodríguez de la Sotta. 


\section{Literatura}

AldCroft, Derek y otros, Europa en crisis, 1919-1939 (Madrid, Editorial Pablo Iglesias, 1991).

BARTH, Boris, Europa nach dem grossen Krieg. Die Krise der Demokratie in der Zwischenkriegszeit 1918-1938 (Frankfurt/M., Campus Verlag, 2016).

Ben Ami, Shlomo, El cirujano de hierro. La dictadura de Primo de Rivera (1923-1930) (Barcelona, RBA Libros, 2012).

Bernedo, Patricio, Prosperidad económica bajo Carlos Ibáñez del Campo, 1927-1929. La dimensión internacional de un programa económico de gobierno, en Historia, 24 (Santiago, 1989), pp. 5-105.

Brahm García, Enrique, Propiedad sin libertad: Chile 1925-1973. Aspectos relevantes en el avance de la legislación socializadora (Santiago, Ediciones de la Universidad de los Andes, 1999).

- La elección presidencial de 1925. El candidato equivocado, en SAN Francisco, Alejandro y Soto, Angel, (editores), Camino a La Moneda. Las elecciones presidenciales en la historia de Chile 1920-2000 (Santiago, Centro de Estudios Bicentenario, 2005), pp. 39-79.

-Algunos aspectos del proceso de socialización del derecho de propiedad en Chile durante el gobierno del general Carlos Ibánez del Campo (1927-1931), en Rechtsgeschichte, 20 (Frankfurt/M., 2012), pp. 234-256.

- La Unión y el Partido Conservador de Valparaiso: ¿una posición divergente en el conservantismo en medio de la crisis institucional de 1925?, en Revista de Estudios Histórico-Jurídicos, 38 (Valparaíso, 2016), pp. 395-419.

- El Partido Conservador frente a la crisis constitucional de 1925, en Revista Chilena de Derecho, 44/1, (Santiago, 2017), pp. 261-285.

Brahm García, Enrique; Bertelsen Repetto, Raúl; Amunátegui Echeverría, Andrés, Régimen de gobierno en Chile. ¿Presidencialismo o Parlamentarismo? 1925-1973 (Santiago, Editorial Jurídica de Chile, 2002).

Collier, Simon y SATER, William, Historia de Chile 1808-1994 (España, Cambrigde University Press, 1998).

Correa, Sofía y otros, Historia del siglo XX chileno (Santiago, Editorial Sudamericana, 2001).

Cruz, Nicolás, El gobierno de Ibáñez a través de la prensa (Santiago, Instituto Chileno de Estudios Humanísticos, 1980), inédito.

Díaz Nieva, José, De la Falange Nacional a la Democracia Cristiana (Madrid, Universidad Nacional de Educación a Distancia, 2000).

Donoso Letelier, Crescente, Notas sobre el origen, acatamiento y desgaste del régimen presidencial 1925-1973, en Historia, 13 (Santiago, 1976), pp. 271-352.

Esponda, Jaime, Pablo Ramirez. El chileno desconocido (Santiago, RIL Editores, 2013).

FERMANDOIs, Joaquín, Abismo y cimiento. Las relaciones entre Chile y Estados Unidos: 1932-1938 (Santiago, Ediciones de la P. Universidad Católica de Chile, 1997).

Gall, Lothar, Zum Ausbildung und Charakter des Interventionsstaates, en Historische Zeitschrift, 227 (Oldenbourg, 1978), pp. 552-570.

Garay, Cristián, El Partido Conservador Chileno 1857-1966. Tendencias internas y conflictos doctrinarios (Tesis Doctoral UNED, Madrid, 2005), inédita.

Góngora, Mario, Ensayo histórico sobre la noción de Estado en Chile en los siglos XIXY $X X$ (Santiago, Editorial La ciudad, 1981). 
HeISE, Julio, Historia de Chile. El régimen parlamentario 1861-1925 (Santiago, Editorial Andrés Bello, 1974).

Ibáñez Santa María, Adolfo, Los ingenieros, el Estado y la política en Chile. Del Ministerio de Fomento (1927) a la Corporación de Fomento de la Producción (1939), en Historia, 18 (Santiago, 1983).

Meller, Patricio, Un siglo de economía política chilena: (1890-1990) (Santiago, Editorial Andrés Bello, 1996).

Mensaje leido por S.E. el Vicepresidente de la República en la apertura del Congreso Nacional el 21 de mayo de 1927 (Santiago, Imprenta Nacional, 1927).

Millar Carvacho, René, Significado y antecedentes del movimiento militar de 1924 en Historia, 11 (Santiago, 1973), pp. 7-102.

Monreal, Enrique, Historia completa y documentada del periodo revolucionario 19241925 (Santiago, Imp. Nacional, 1929).

NipPerdey, Thomas, Deutsche Geschichte 1866-1918, Bd. II, Machtstaat vor der Demokratie (München, C.H. Beck, 1993).

Nocera, Raffaele, Duhart, Carmen Gloria, Alarcón, Camilo, Italia a través de los informes diplomáticos chilenos, 1924-1940, (Santiago, Colección de Informes Diplomáticos. Ministerio de Relaciones Exteriores de Chile, 2017).

Nunn, Frederick, Chilean Politics, 1920-1931: the honorable Missions of the Armed Forces (Alburquerque, New Mexico, University of New Mexico Press, 1970).

Payne, Stanley, Historia del Fascismo (Barcelona, Planeta, 1995).

Pereira, Teresa, El Partido Conservador 1930-1965. Ideas, figuras y actitudes (Santiago, Fundación Mario Góngora, 1994).

Scott, Harry, Pensando el Chile Nuevo. Las ideas de la revolución de los tenientes y el primer gobierno de Ibáñez, 1924-1931 (Santiago, Centro de Estudios Bicentenario, 2009).

Silva, Patricio, En el nombre de la razón. Tecnócratas y política en Chile (Santiago, Ediciones Universidad Diego Portales, 2010).

STOLLEIS, Michael, Geschichte des öffentlichen Rechts in Deutschland, Bd. III (München, C.H. Beck, 1999).

Vial Correa, Gonzalo, Historia de Chile (1891-1973), Vol. III, Arturo Alessandri y los golpes militares (1920-1925) (Santiago, Santillana, 1986).

Vial Correa, Gonzalo, Historia de Chile (1891-1973), Vol. IV, La dictadura de Ibáñez (1925-1931) (Santiago, Editorial Fundación, 1996).

Vicuña, Carlos, La tiranía en Chile (Santiago, Ediciones LOM, 2002).

Villalobos, Sergio y Sagredo, Rafael, El proteccionismo económico en Chile, siglo XIX (Santiago, Instituto de Estudios Superiores Blas Cañas, 1987). 
